\title{
Evaluation of the in-depth temperature sensing performance of Eu- and Dy-doped YSZ in air plasma sprayed thermal barrier coatings
} DOI:

10.1016/j.surfcoat.2017.03.029

\section{Document Version}

Accepted author manuscript

Link to publication record in Manchester Research Explorer

Citation for published version (APA):

Yang, L., Peng, D., Zhao, C., Xing, C., Guo, F., Yao, Z., Liu, Y., Zhao, X., \& Xiao, P. (2017). Evaluation of the indepth temperature sensing performance of Eu- and Dy-doped YSZ in air plasma sprayed thermal barrier coatings. Surface and Coatings Technology, 316, 210-218. https://doi.org/10.1016/j.surfcoat.2017.03.029

Published in:

Surface and Coatings Technology

\section{Citing this paper}

Please note that where the full-text provided on Manchester Research Explorer is the Author Accepted Manuscript or Proof version this may differ from the final Published version. If citing, it is advised that you check and use the publisher's definitive version.

\section{General rights}

Copyright and moral rights for the publications made accessible in the Research Explorer are retained by the authors and/or other copyright owners and it is a condition of accessing publications that users recognise and abide by the legal requirements associated with these rights.

\section{Takedown policy}

If you believe that this document breaches copyright please refer to the University of Manchester's Takedown Procedures [http://man.ac.uk/04Y6Bo] or contact uml.scholarlycommunications@manchester.ac.uk providing relevant details, so we can investigate your claim.

\section{OPEN ACCESS}




\title{
Evaluation of the in-depth temperature sensing performance of Eu- and
}

Dy-doped YSZ in air plasma sprayed thermal barrier coatings

Lixia Yang ${ }^{1,2}$, Di Peng ${ }^{1,3}$, Chunshan Zhao ${ }^{1,2}$, Chen Xing ${ }^{1,2}$, Fangwei Guo ${ }^{1,2}$, Zhiqi Yao ${ }^{5}$, Yingzheng Liu ${ }^{1,3}$, Xiaofeng Zhao ${ }^{1,2, *}$, Ping Xiao ${ }^{4}$

1 Gas Turbine Research Institute, Shanghai Jiao Tong University, Shanghai 200240, China

2 Shanghai Key Laboratory of Advanced High-temperature Materials and Precision Forming, Shanghai Jiao Tong University, Shanghai, 200240, China

3 Key Lab of Education Ministry for Power Machinery and Engineering, School of Mechanical Engineering, Shanghai Jiao Tong University, Shanghai, 200240, China

4 School of Materials, University of Manchester, Grosvenor Street, Manchester M1 7HS, UK

5 Corporate Technology, Siemens Ltd. China, 7 Wangjing Zhonghuan Nanlu, Beijing 100102, China

\begin{abstract}
In-depth temperature sensing in air plasma sprayed (APS) thermal barrier coatings (TBCs) has been achieved with europium $(\mathrm{Eu})$ and dysprosium (Dy) doped yttria stabilized zirconia (YSZ) sensor coatings. The luminescence properties of YSZ:Eu and YSZ:Dy, including spectrum, intensity and lifetime, were evaluated and their temperature sensing performances were compared using a lifetime-based measurement system. Both sensor TBCs display excellent temperature sensitivity in high temperature environment $\left(400-800{ }^{\circ} \mathrm{C}\right.$ for YSZ:Eu, 500-900 ${ }^{\circ} \mathrm{C}$ for YSZ:Dy) with a topcoat thickness up to $300 \mu \mathrm{m}$. It was found that the upper limit of temperature sensing was determined by the ratio between luminescence intensity and background thermal radiation (signal-background-ratio). YSZ:Dy showed higher luminescent intensity than YSZ:Eu at elevated temperatures, and therefore displayed better temperature sensing performance with an increased limit. The effect of topcoat thickness on the temperature sensing performance was also evaluated, showing that the attenuation factor of YSZ increased significantly with topcoat thickness.
\end{abstract}

\footnotetext{
${ }^{*}$ Corresponding author Tel./fax: +8621 54742561.

E-mail address: xiaofengzhao@sjtu.edu.cn (Xiaofeng Zhao).
} 
Interestingly, it was found that the topcoat attenuation factor gradually decreased as temperature increased, which improved the temperature sensing performance of sensor TBCs at elevated temperature. The findings in the temperature sensing of APS TBCs provide basis for the future development of on-line APS TBCs temperature monitoring technology.

Keywords: Thermal barrier coatings, temperature sensing, air plasma spray, luminescence, decay lifetime, signal-background-ratio

\section{Introduction}

Thermal barrier coatings (TBCs) have shown great promise of thermal protection in a variety of applications involving high heat flux and/or moderately high temperature environments, especially for aero engines and gas turbines [1-3]. The lifetime of TBCs fundamentally depends on the temperature at the metallic bond coat/ceramic interface. Consequently, accurate temperature measurement under engine operating conditions is of paramount importance if reliable life predictions are to be made and novel cooling schemes are to be designed [4]. The application of conventional contact-type temperature measurement is difficult or even impossible due to the inaccessibility and the high-speed motion of the engine components [5]. Similarly, the translucent nature of most ceramic TBCs poses problems for pyrometry when the $\mathrm{TBC}$ is under a temperature gradient since the thermal radiation sampled by the pyrometer originates from $\mathrm{TBC}$ at different depths and temperatures $[1,5,6]$. An alternative method is "thermal barrier sensor coatings" (sensor TBCs) technique, which was proposed by Feist et al. [7] and has shown the ability to overcome these difficulties [8-11]. Selected rare-earth ions are incorporated into the crystal structure of the ceramic TBC to form sensor TBCs. The luminescence lifetime of the rare-earth material is temperature-dependent due to thermal quenching effect, so that the sensor $\mathrm{TBC}$ acts as a thermographic phosphor as well as a protective thermal barrier.

Previous works $[4,12,13]$ have shown the possibility of in-depth temperature measurement using europium $(\mathrm{Eu})$ or dysprosium (Dy) doped ceramic $\mathrm{TBC}-\mathrm{yttria}$ 
stabilized zirconia (YSZ) deposited by electron-beam physical vapor deposition (EB-PVD). The temperature sensing range of EB-PVD sensor TBCs is mainly limited by the short luminescence decay lifetime rather than the low signal level at high temperatures, since the coatings typically have columnar microstructure with relatively high light transparency to allow in-depth temperature measurements [12-15]. However, compared to EB-PVD TBCs, coatings deposited by APS typically have parallel structures with relatively high scattering coefficient and low transmittance to significantly attenuate excitation and luminescence intensities $[1,6,16]$. The low luminescence intensity at high temperatures becomes the key limitation for the in-depth temperature sensing performance for APS TBCs. Therefore, it is of great significance to investigate the effects of coating thickness on the sensing performance. Feist and Heyes [1] demonstrated in-depth temperature sensing up to $800{ }^{\circ} \mathrm{C}$ with a topcoat as thick as $500 \mu \mathrm{m}$ deposited by APS and their results showed that the topcoat thickness had no obvious effects on the upper limit of temperature. However, our previous work clearly shown that the existence of the YSZ topcoat caused significant signal attenuation and therefore a decrease in the upper sensing limit [17]. So a more detailed study is required to shed more light on this problem. Additionally, in all of previous investigations on APS sensor TBCs, only the Dy is selected to be the luminescence dopant in the YSZ hosts [1, 16-21] and no research has been carried out to investigate the temperature sensing using the YSZ:Eu sensor coating. It has been shown that the scattering coefficient of YSZ topcoat decreases with wavelength [22]. As a result, the APS TBCs with YSZ:Eu sensor coating, which has a longer luminescence wavelength $(\sim 606 \mathrm{~nm})$ than YSZ:Dy $(\sim 585 \mathrm{~nm})[23,24]$, could exhibit higher luminescence intensity and thus better temperature sensing capability for in-depth temperature measurements.

Therefore, the main objective of this study is to assess and compare the in-depth temperature sensing performance of Eu and Dy doped YSZ sensor coatings employed in APS TBCs. These sensor TBCs were prepared using a commercial plasma spraying process and an optical measurement system was developed for lifetime-based temperature sensing. The signal-to-background-ratio (SBR) (defined as the ratio of 
the luminescent signal and the background signal (mostly thermal radiation)) was introduced as a metric for evaluating the temperature sensing performance of sensor TBCs with different topcoat thickness. The temperature-dependent luminescence intensity, thermal radiation and transmittance of YSZ topcoat were investigated with the focus on their effect on the temperature sensing performance. And finally the effect of YSZ topcoat thickness on the temperature sensing was investigated. The findings in the current study provide basis for the future development of on-line TBC temperature monitoring technology

\section{Experimental setup}

\subsection{Specimen preparation}

Powder specimens of $8 \mathrm{wt} \%$ YSZ:Eu $\left(\mathrm{Eu}^{3+}: 1 \mathrm{~mol} \%\right)$ and $8 \mathrm{wt} \% \mathrm{YSZ}: \mathrm{Dy}\left(\mathrm{Dy}^{3+}: 1\right.$ mol\%) were prepared by reverse co-precipitation. The reverse co-precipitation was selected for the preparation of the materials to avoid segregation of the cations and ensure molecular mixing of the dopant into the host material [25]. The starting materials for the specimen preparations included $\mathrm{ZrOCl}_{2} \cdot 8 \mathrm{H}_{2} \mathrm{O}$ (99.9 \%), $\mathrm{Eu}_{2} \mathrm{O}_{3}$ (99.99\%), $\mathrm{Dy}_{2} \mathrm{O}_{3}(99.99 \%), \mathrm{Y}_{2} \mathrm{O}_{3}(99.99 \%), \mathrm{HNO}_{3}$, and ammonium hydroxide. $\mathrm{A}$ procedure for the specimen synthesis is described as follows: $\mathrm{Eu}_{2} \mathrm{O}_{3}$ and $\mathrm{Y}_{2} \mathrm{O}_{3}$ were weighed according to the target composition. They were first dissolved in nitric acid under heating. After $\mathrm{Eu}_{2} \mathrm{O}_{3}$ and $\mathrm{Y}_{2} \mathrm{O}_{3}$ were completely dissolved, the excess nitric acid was removed at elevated temperature. Then the $\mathrm{ZrOCl}_{2} \cdot 8 \mathrm{H}_{2} \mathrm{O}$ and de-ionized water was added to obtain the mixture solution and then magnetically stirred for $24 \mathrm{~h}$. Finally, the mixed solution was slowly dropped into aqueous ammonia solution with constant $\mathrm{PH}$ of 9 to guarantee instantaneous precipitation of the mixed cation solution. The precipitate was filtered, washed with distilled water and ethanol and then dried at $120{ }^{\circ} \mathrm{C}$ for $24 \mathrm{~h}$. In the last step, the dried gel were calcined at $950{ }^{\circ} \mathrm{C}$ for $12 \mathrm{~h}$ to obtain the phosphor oxide. The obtained nano-sized powders were reconstituted into micrometer-sized granules by electrospraying to obtain good flowability for plasma spraying [26].

The sensor TBCs embedded with YSZ:Eu or YSZ:Dy coating were prepared by air 
plasma spraying system on commercial Hastalloy X alloy (22Cr18Fe9Mo1.5W0.10C, in wt\%, balanced by Ni) substrates of a thickness of $4 \mathrm{~mm}$. The substrates were ultrasonically cleaned, grit blasted by $\mathrm{Al}_{2} \mathrm{O}_{3}$ mesh and then placed in an air plasma spray system for overlaying with a NiCoCrAlY (AMDRY 365-2) bond coating. The ceramic coating consisted of a sensor coating (YSZ:Eu or YSZ:Dy) followed by an overcoat of commercial $8 \mathrm{wt} \%$ YSZ (Oerlikon Metco 204B-NS, HOSP). To study the effect of the luminescent signal of YSZ on the lifetime measurement and investigate any possibilities of the existence of the $\mathrm{Eu}^{3+}$ or $\mathrm{Dy}^{3+}$ impurities in the YSZ topcoat, a reference specimen was also prepared. The specimen consisted of an undoped YSZ topcoat without a sensor coating below, and a bond coat on the substrate. The spray parameters are given in Table 1. Identical spray parameters were employed for spraying the sensor coating and topcoat with the purpose of minimizing the alterations in the ceramic coating microstructure. Meanwhile, the YSZ topcoat of the reference specimen was produced in the same deposition run with the TBC sensor specimen. Substrate dimensions were approximately $30 \mathrm{~mm} \times 30 \mathrm{~mm}$. The bond coats were about $150 \mu \mathrm{m}$ thick, while the sensor coating thickness was limited to $40 \mu \mathrm{m}$. The thickness of the topcoats of sensor specimens were $0,70,150$ and $280 \mu \mathrm{m}$, and the thickness of the YSZ topcoat of the reference specimen was $280 \mu \mathrm{m}$.

\subsection{Phase and microstructure characterization}

The phases of the obtained powder specimens were identified by Raman spectroscopy (Horiba Jovin Yvon, LabRAM HR Evolution). A $532 \mathrm{~nm}$ laser was used as the excitation source with a power of $60 \mathrm{~mW}$. The laser beam was focused on the coating surface through a $\times 50$ objective lens.

The microstructures and the thicknesses of the YSZ topcoat and the sensor coatings were examined by scanning electron microscopy (SEM, Zeiss Super 55). Luminescence images were also obtained from metallographic cross-sections of specimens with an optical microscope (SZ51, Olympus) under the UV illumination provided by a $405 \mathrm{~nm}$ diode laser (OEM-HD-405, CNI Laser) in continuous mode which was coupled with a $515 \mathrm{~nm}$ long-pass filter. 


\subsection{Transmittance measurement}

Freestanding APS YSZ coatings with thicknesses of 70, 150 and $280 \mu \mathrm{m}$ were prepared for transmittance measurements by dissolving the bond coat and substrate of the TBCs without a sensor coating using acids $\left(\mathrm{HCl}\right.$ and $\left.\mathrm{HNO}_{3}\right)$. The coatings were also produced in the same deposition run with the YSZ topcoat of the TBC sensor specimens to avoid variations in porosity. Transmittance spectra were acquired using a spectrophotometer (Perkin Elemer Lambda 750s) equipped with a $60 \mathrm{~mm}$ diameter integrating sphere accessory. Deuterium and tungsten lamps were used as the light source to provide radiation to the specimen (normal to the surface). Spectra in the 0-800 $\mathrm{nm}$ wavelength range were collected at room temperature.

\subsection{Luminescence measurement}

The luminescence properties of the excited sensor coating were obtained using the set-up shown in Fig.1. The sensor TBCs specimens were placed in a high temperature tube furnace (SGL-1400, SIOMM) with a working temperature range of 300 to 1250 ${ }^{\circ} \mathrm{C}$ and an accuracy of $\pm 2{ }^{\circ} \mathrm{C}$. The specimen was excited using a $405 \mathrm{~nm}$ diode laser being modulated by a function generator (Tektronix, AFG1022), instead of a 355/532 nm Nd:YAG laser commonly used in previous studies. This portable, low-cost laser could be modulated up to $30 \mathrm{kHz}$ in comparison to $10-20 \mathrm{~Hz}$ for a Nd:YAG laser, which greatly improved the overall sampling rate. This is especially useful at high temperatures where the average of multiple measurements is usually required for achieving a sufficient signal-to-noise ratio. The luminescent signal first went through a sight tube and was collected by a PMT (Photo Multiplier Tube) module (Hamamatsu, h9305-03) through a camera lens (Nikon $60 \mathrm{~mm}, \mathrm{f} / 2.8$ ). A band-pass filter $(550-625 \mathrm{~nm})$ was installed before the camera lens to exclude the excitation light and reduce the thermal radiation at high temperatures. The current signal from the PMT was converted to voltage through a resistance box $(\mathrm{R}=1 \mathrm{k} \Omega)$ and then recorded by an oscilloscope (Tektronix, DPO2002B) with a sampling rate of 3.125 MHz. For each measurement, the PMT signal was averaged over 512 laser pulses to ensure a good signal-to-noise ratio. A K-type thermocouple (XC-K-14-25, 0-1090 ${ }^{\circ} \mathrm{C}, \pm 1 \%$ ) 
was placed close to the $\mathrm{TBC}$ specimen to monitor the temperature during the calibration. Insulation material (asbestos) was placed on both ends of the tube to improve the temperature uniformity within the furnace. For an observation of the luminescence spectra, the PMT system was replaced by an Ocean Optics USB 2000 grating spectrometer with a photodiode array housed in a personal computer and triggered by the laser.

\subsection{Data processing}

Fig.2 shows an excitation pulse (in blue) and sample decay curves of YSZ:Eu (in black) and YSZ:Dy specimens (in red) recorded by the oscilloscope. In the simplest, the luminescent response of a phosphor doped YSZ to a pulsed excitation is a single-exponential decay [25]:

$$
I=I_{0} \cdot \exp (-t / \tau)
$$

where $\tau$ is the lifetime of the phosphor, $I$ is the measured intensity decay and $I_{0}$ is the intensity at the start of the decay. For some phosphor doped YSZ, the luminescence decay consists of two single-exponential decays [25]:

$$
I=I_{1} \cdot \exp \left(-t / \tau_{1}\right)+I_{2} \cdot \exp \left(-t / \tau_{2}\right)
$$

The feature of luminescence decay can be identified using the curve of logarithm of intensity, as shown in Fig.2 (inset). It can be seen that the YSZ:Eu is a single-exponential decay [27], and the YSZ:Dy consists of two exponential components due to the non-linear decrease with time. The non-exponential decay of YSZ:Dy luminescence is due to strong self-interaction [5, 28]. Additionally, from the Fig.2, it can been seen that at the stop of the excitation, there exist a vertical downward section $\left(I_{\mathrm{v}}\right)$. This is the signal of YSZ, which has a very short luminescence lifetime and thus has negligible effect on the measurement of the YSZ:Eu or YSZ:Dy specimens (see Appendix for details).

The standard approach for calculating $\tau$ includes three steps: the background subtraction, the intensity normalization and the linear curve-fitting. The background level $\left(I_{\mathrm{BG}}\right)$ was evaluated using the average of intensities immediately before the start 
of the excitation pulse, as shown by the shaded area in Fig.2. This background value $\left(I_{\mathrm{BG}}\right)$ and the YSZ luminescence value $\left(I_{\mathrm{v}}\right)$ were subtracted from the intensity data during the luminescent decay. Then all decay data were normalized by the intensity value $\left(I_{0}\right)$. Finally, a linear curve-fit was applied to the logarithm of normalized decay data to find the decay lifetime. For the YSZ:Dy specimens, the slope of the slower decay curve was used for temperature measurement, as the black dash lines show (Fig.2 (inset)). Because the values obtained from the exponential fits can be sensitive to the choice of the start and end of fitting window, a precisely defined time window is required which is only related to the decay time and independent of the settings of the acquisition system, as described by the previous work [29-32]. In this study, the fitting window starts at and ends at 0.5 times and 4.5 times of decay time, respectively, which yielded good results [31]. The initial intensity $I_{0}$ can also be used to investigate the relation between luminescent intensity and temperature, provided that the sensor coating is excited with a sufficiently long pulse.

\section{Results}

\subsection{Phase and microstructure characterization}

Fig.3 shows the Raman spectra of the powder YSZ:Eu and YSZ:Dy specimens prepared using the reverse co-precipitation method. The spectra with six Raman peaks confirm that the YSZ is single-tetragonal phase. Fig.4 (a) shows the SEM images of the surface and cross-section morphology (inset) of the reconstituted powder specimens. The images reveal that the reconstituted powders were spherical and porous with size ranging from 40 to $100 \mu \mathrm{m}$. The powder possesses a suitable particle size, a low density and good flowability which is suitable to plasma spraying. Fig.4 (b) shows the cross-sectional SEM image of the sensor TBCs specimen: a YSZ:Eu sensor coating with approximately $40 \mu \mathrm{m}$ thickness is located at the base of the ceramic coating, and an undoped YSZ coating lies on top with approximately $280 \mu \mathrm{m}$ thickness and a porosity of about $25 \%$. The enlarge SEM image of APS YSZ topcoat is also illustrated in Fig.4 (c), which exhibits the microcracks, pores, and lamellar structure. These are similar to that of a conventional TBCs and the sensor coating was 
achieved without stratification of the APS YSZ. The microstructure of YSZ:Dy specimen is the same with that of YSZ:Eu specimen. The luminescence image of the specimen is also obtained and shown in Fig.4 (d), which verified the deposition of a distinct YSZ:Eu coating. The YSZ:Eu coating clearly displays red emission under the excitation of a $405 \mathrm{~nm}$ light source. The whole image appears to be yellow due to the use of a $515 \mathrm{~nm}$ color glass filter.

\subsection{Luminescence spectra}

Luminescence spectra excited by a $405 \mathrm{~nm}$ laser were recorded for the powder specimens of YSZ:Eu and YSZ:Dy at room temperature and are shown in Fig.5. The luminescent transitions of YSZ:Eu were observed between 570 and $670 \mathrm{~nm}$. The strongest lines observed at around 591 and $606 \mathrm{~nm}$ are generally the ${ }^{5} \mathrm{D}_{0} \rightarrow{ }^{7} \mathrm{~F}_{1}$ and ${ }^{5} \mathrm{D}_{0} \rightarrow{ }^{7} \mathrm{~F}_{2}$ transitions, respectively [25, 33]. The former is a magnetic dipole allowed transition and is mostly independent of the host material [25]. The latter at around 606 $\mathrm{nm}$ corresponds to the electronic dipole transition [25]. The luminescence of YSZ:Dy was observed between 460 and $630 \mathrm{~nm}$. The emission at around $585 \mathrm{~nm}$ which corresponds to ${ }^{4} \mathrm{~F}_{9 / 2} \rightarrow{ }^{6} \mathrm{H}_{13 / 2}$ transition, is most intense and was used for the lifetime decay measurements [23]. The $480 \mathrm{~nm}$ band is due to the ${ }^{4} \mathrm{~F}_{9 / 2} \rightarrow{ }^{6} \mathrm{H}_{15 / 2}$ transition.

The luminescence spectra of the YSZ:Eu or YSZ:Dy TBCs specimens show slight difference from those of the powder specimens, as shown in Fig.6 (a-b), where the intensities have been normalized using the highest intensity (the $606 \mathrm{~nm}$ peak of the YSZ:Eu specimen without YSZ topcoat). A broadband feature can be seen between 450 to $700 \mathrm{~nm}$ from the spectra, which is believed to be the luminescence spectrum of YSZ (see Appendix for details). To better display this broadband feature, the luminescence spectra of YSZ:Eu are also plotted on a logarithmic scale (inset). Comparing the luminescence from the spectra, the intensities of YSZ:Eu specimens are 2 to 3 times larger than those of YSZ: Dy specimens at room temperature with the same YSZ topcoat thickness (Fig.6 (a-b)). It is also clear that the luminescent intensities of YSZ:Eu and YSZ:Dy specimens decrease significantly as topcoat thickness increases. Finally, considering that the luminescence lines at around 591 and 
$606 \mathrm{~nm}$ for YSZ:Eu have the same luminescence lifetimes [34], a band-pass filter of 550-625 nm was selected for the collection of the luminescent signal based on the emission spectra of YSZ:Eu and YSZ:Dy specimens.

\subsection{Lifetime measurements}

The lifetime-based temperature calibration results are presented in Fig.7 (a-b) for all TBCs specimens with four different thicknesses of YSZ topcoat. The YSZ:Eu specimens provide measurable responses from the room temperature up to about 800 ${ }^{\circ} \mathrm{C}$, while the YSZ:Dy signals can be detected up to almost $900{ }^{\circ} \mathrm{C}$. For the YSZ:Eu specimens, the lifetime values are around $2 \mathrm{~ms}$ at the room temperature, and they show weak dependency on the temperature from the room temperature to about 400 ${ }^{\circ} \mathrm{C}$. Then the temperature sensitivity suddenly increases, and a linear relation is observed between $T$ and $\log (\tau)$. The lifetime drops to about $1.5 \mu$ s at $800{ }^{\circ} \mathrm{C}$. The lifetime-temperature curves of the YSZ:Dy TBCs specimens show the same two region behavior, except the quenching temperature moves to higher temperatures $\left(\sim 500{ }^{\circ} \mathrm{C}\right)$. And then it starts to decrease monotonically to $1 \mu$ s at $900{ }^{\circ} \mathrm{C}$ due to the considerably short lifetime to reach the limit of the PMT system $(\sim 1 \mu \mathrm{s})$. These lifetime values agree well with the data from previous studies [4, 13], which were measured for the YSZ:Dy $2 \%$ and YSZ:Eu 2\% EB-PVD specimens. Also, it can be seen that the lifetime does not change with the topcoat thickness, as expected, while the upper limit of temperature sensing is reduced as the topcoat thickness increased, which will be discussed in detail in the next section.

The lifetime results clearly show that YSZ:Eu has a temperature calibration curve with a higher slope (-0.0091) than YSZ:Dy (-0.0078). The luminescent lifetime values are generally lower for YSZ:Eu at the same temperature within the sensing range. This indicates that YSZ:Eu has a better precision of measurement, since the uncertainty in temperature is a function of the curve slope. However, YSZ:Dy has a higher sensing limit, which makes it preferable for high temperature measurement. 


\section{Discussion on temperature sensing performance}

As shown by the lifetime calibration results, the upper limit of temperature sensing was clearly reduced as the topcoat thickness increased. At high temperatures, the weak luminescent signal is barely detectable under strong thermal radiation, which leads to increased measurement error. Eventually, the temperature sensing becomes unfeasible at sufficiently high temperatures. Additionally, the YSZ:Dy specimens show higher temperature upper limit, although they produce much low luminescence intensities than the YSZ:Eu specimens at room temperature (Fig.6 (a-b)).

In order to evaluate the temperature sensing performance of APS sensor TBCs with different topcoat thickness and different sensor coating, the ratio between luminescence intensity $\left(I_{0}\right)$ and the background thermal radiation level $\left(I_{\mathrm{BG}}\right)$ was introduced as a metric. This signal-background-ratio (SBR) actually determines the upper limit of temperature sensing as discussed earlier. The relations between the temperature and SBR of YSZ:Eu and YSZ:Dy specimens with four different thicknesses of YSZ topcoat are presented in Fig.8 (a-b), respectively. Several important observations can be made based on the results:

1) There is a general trend that the SBR decreases non-exponentially (shown as slightly curved lines) as temperature increases for all specimens with a certain YSZ topcoat thickness, which is consistent with the previous report studied by Allison et al. [9]. As the temperature increases, the low SBR value results in significant measurement error $\left( \pm 7^{\circ} \mathrm{C}\right.$ uncertainty for a SBR value of 0.05) [17]; 2) YSZ:Dy specimens have larger SBR values than YSZ:Eu with the same topcoat thickness at the same temperature; 3) The SBR reduces significantly as the YSZ topcoat thickness increases at a certain temperature for both YSZ:Eu and YSZ:Dy specimens; 4) It is interesting to see that the SBR of the thicker YSZ topcoat specimens drops more slowly than that of the thinner ones as temperature increases.

It should be noted that SBR is primarily determined by the following three factors: luminescence intensity; thermal radiation and transmittance of YSZ topcoat. These factors are discussed in detail in the rest of this section to reveal the possible reasons 
responsible for the variation of SBR values with temperature and the YSZ topcoat thickness.

\subsection{Luminescence intensity}

Fig.9 shows the temperature dependence of the luminescence intensities of both the YSZ:Eu (in black) and YSZ:Dy (in red) sensor coatings without the YSZ topcoat after being normalized by the maximum intensity. The intensity of YSZ:Eu specimen decreases slowly with increasing temperature initially and then starts to drop exponentially as the quenching temperature is reached around $400{ }^{\circ} \mathrm{C}$. However, the luminescence intensity of YSZ:Dy increases slightly from room temperature to $250{ }^{\circ} \mathrm{C}$ before it starts to decrease. This is due to the slow increase in absorption coefficient with increasing temperature [35]. The quenching temperature is around $500{ }^{\circ} \mathrm{C}$ which is higher than that of YSZ:Eu.

The comparison between the intensity characteristics of YSZ:Eu and YSZ:Dy reveals that although the YSZ:Eu has a larger intensity at low temperatures, the lower quenching temperature and the steeper slope afterwards result in lower intensities at elevated temperatures than those of YSZ:Dy (Fig.9). Therefore, the YSZ:Dy specimens have higher SBR values and thus better temperature sensing performance than YSZ:Eu, considering that the amount of thermal radiation should be identical at the same temperature. The more significant extinction of the YSZ:Eu luminescence is caused by the depopulation of the ${ }^{5} \mathrm{D}_{0}$ emission level via charge transfer state at high temperature, which offers an additional path for non-radiative relaxation [13].

\subsection{Thermal radiation}

The normalized thermal radiation intensities of YSZ:Eu specimens with different topcoat thickness as a function of temperature are illustrated in Fig.10. Here, all intensity values were normalized by the maximum intensity of the $150 \mu \mathrm{m}$ specimen. Clearly, the background thermal radiation increases non-exponentially with temperature, which leads to the non-exponential relation between SBR and temperature observed in Fig.8. Moreover, it can be seen that the thickness of YSZ 
topcoat has no effect on the thermal radiation intensities. This suggests that the effect of YSZ topcoat thickness on the SBR can only be resulted from the variations in the transmittance of YSZ topcoat. Note that there are some deviations at low temperatures $\left(\leq 650^{\circ} \mathrm{C}\right)$ which are due to the increased measurement error of weak signal. The background level is due to both the surface emission of the TBCs specimens and the reflected radiation from the hot environment [6]. The effect of changing emittance with TBC thickness may be offset by changes in reflections of the surroundings.

\subsection{Attenuation factor of YSZ topcoat}

The attenuation factor of YSZ topcoat at certain temperature can be obtained by one minus the ratio of all values of $I_{0}$ to $I_{0}$ of the specimen without YSZ topcoat, which represents the overall amount of signal attenuation with respect to the specimen without topcoat. The attenuation factor values of YSZ with different topcoat thickness as a function of temperature for YSZ:Eu and YSZ:Dy specimens are shown in Fig.11

$(a-b)$. It can be seen that the attenuation factor of YSZ topcoat increases significantly as the thickness increases. This is consistent with the transmittance results (shown in Fig. 12), considering that the attenuation factor is inversely proportional to the transmittance [36]. Fig. 12 shows the transmittance results for APS 8 wt $\%$ YSZ topcoat with thicknesses of 70,150 and $280 \mu \mathrm{m}$, which exhibits a decreasing trend as the coating thickness increases due to the high surface reflections and volume scattering nature of the APS coating [22]. It is noted that transmittance values obtained in this study are close to those reported by Yang et al. for 100 and $200 \mu \mathrm{m}$ thick APS YSZ coatings [37, 38], but are higher than that reported by Eldridge et al. for a $172 \mu \mathrm{m}$ thick APS YSZ [39]. The difference in transmittance could be attributed to the different microstructure, specifically, the distribution and size of scattering sites, such as grain boundaries, splat boundaries, cracks and pores in the YSZ topcoat. Those factors are strongly influenced by the spraying parameters [22, 37-40].

Also, it is clear the attenuation factor decreases as temperature increases for both YSZ:Eu and YSZ:Dy specimens from 600 to $900{ }^{\circ} \mathrm{C}$ in the detected wavelength range from 550 to $625 \mathrm{~nm}$. The variation in attenuation factor is likely related to the 
broadband emission from YSZ. As shown in Appendix, the luminescence of YSZ topcoat is produced due to $\mathrm{F}$ or $\mathrm{F}^{+}$color center transition. These types of defects are usually eliminated after heating in an oxygen containing environment [41]. As a result, the YSZ absorption and emission are reduced, and more excitation light can reach the sensor coating. Therefore, the decreased attenuation with temperature is likely due to the reduction of these oxygen vacancy associated defect states.

It is also noted that the YSZ:Eu have lower attenuation factor than YSZ:Dy for the same thickness of YSZ topcoat for the same thickness of YSZ topcoat. This is probably due to the difference in luminescence spectra (Fig.6). The strongest luminescence peak of YSZ:Eu is at a longer wavelength $(606 \mathrm{~nm})$ than that of YSZ:Dy $(585 \mathrm{~nm})$. Since that the transmittance of freestanding YSZ coating increases with wavelength (Fig.12), the attenuation factor of luminescence of YSZ:Eu as it travels through YSZ topcoat is less than that of YSZ:Dy. But due to its lower luminescence intensity (Fig.9), the overall SBR values of YSZ:Eu are still lower than that of YSZ:Dy as previously discussed.

\section{Conclusion}

The in-depth temperature sensing performance of the Eu- and Dy-doped YSZ APS sensor TBCs based on the luminescence lifetime was evaluated and compared using a remote temperature measurement system. It was found that both sensor TBCs displayed excellent temperature sensitivity in high temperature environment (400-800 ${ }^{\circ} \mathrm{C}$ for YSZ:Eu, $500-900{ }^{\circ} \mathrm{C}$ for YSZ:Dy) with a topcoat thickness up to $300 \mu \mathrm{m}$. The YSZ:Dy specimens showed higher upper limits of temperature sensing than that of YSZ:Eu, and this limit was reduced as the YSZ topcoat thickness increased for both YSZ:Eu and YSZ:Dy specimens. The signal-to-background-ratio (SBR) was found to be a key factor that determined the upper sensing limit due to the significant signal attenuation from the TBC topcoat. The SBR value is directly related to the temperature-dependent luminescence intensity, the thermal radiation and the transmittance of YSZ topcoat.

YSZ:Dy showed higher luminescent intensity than YSZ:Eu at elevated temperatures due to the lower quenching temperature and the steeper slope of the intensity-temperature curve. As a result, YSZ:Dy displayed better temperature sensing 
performance at high temperatures with an increased upper limit. The thermal radiation signal exhibited a non-exponential increase with temperature, which was found to be independent of the YSZ topcoat thickness. The attenuation factor of YSZ topcoat increased significantly as the topcoat thickness increased. Interestingly, it was found that the topcoat attenuation factor gradually decreased with temperature, which actually improved the temperature sensing performance of sensor TBCs at elevated temperature.

\section{Appendix A: Discussion of the luminescent signal from YSZ topcoat}

As shown in Fig.6 (a-b), the luminescence spectra of YSZ:Eu or YSZ:Dy specimens exhibit a broadband feature, which is different from the spectra of their powder specimens. The origin of the broadband and its influence on the luminescence lifetime measurement are discussed here. The broadband signal decreases in intensity with laser exposure (Fig.A.1 (a-b)), which are acquired with a time interval of $1 \mathrm{~s}$ under the excitation of a continuous light source. After about $60 \mathrm{~s}$, the intensity of broadband is almost constant. The spectral information presented in Fig.6 (a-b) is measured after the luminescence intensities of YSZ are stabilized. The increased intensity of the broadband signal with the topcoat thickness (except for the $0 \mu \mathrm{m}$ specimen), the emission wavelengths as well as the laser exposure effect indicate that the broadband is the luminescence from YSZ as a result of the $\mathrm{F}_{\text {or }} \mathrm{F}^{+}$color center transitions, where the $\mathrm{F}$ and $\mathrm{F}^{+}$are oxygen vacancies with one or two trapped electrons, respectively [41, 42]. In addition, the intensity of the broadband of YSZ:Eu and YSZ:Dy specimens without YSZ topcoat are higher than that of TBCs specimen with $70 \mu \mathrm{m}$ topcoat (Fig.6 (a-b)), which may be due to the larger defect concentration of YSZ.

To study the effect of the luminescent signal of YSZ on the lifetime measurement and investigate any possibilities of the existence of the $\mathrm{Eu}^{3+}$ or $\mathrm{Dy}^{3+}$ impurities in the YSZ topcoat, measurements of emission spectrum and decay curve were made on a YSZ topcoat without a sensor layer below on the bond coated substrate. Fig.A.2 shows the luminescence spectrum, and the decay curve of the YSZ topcoat compared with that of the sensor specimens after normalized by $I_{0}$ (inset). It is clear that the emission spectrum of the YSZ topcoat don't exhibit any emission feature of $\mathrm{Eu}^{3+}$ or $\mathrm{Dy}^{3+}$. 
Meanwhile, the luminescence lifetime of YSZ topcoat is zero from its decay curve. Therefore, it is confirmed the YSZ luminescent signal has no effect on the luminescence lifetime measurements of YSZ:Eu and YSZ:Dy sensor specimens and there are no $\mathrm{Eu}^{3+}$ or $\mathrm{Dy}^{3+}$ impurities in the YSZ topcoat.

\section{Acknowledgements}

The authors would thank the financial support from Siemens Ltd., China, the "1000 Plan Program", the Program for Professor of Special Appointment (Eastern Scholar) at Shanghai Institutions of Higher Learning (No.SHDP201303), the National Natural Science Foundation of China (No.51271120).

\section{References}

[1] J.P. Feist, A.L. Heyes, Photo-stimulated phosphorescence for thermal condition monitoring and nondestructive evaluation in thermal barrier coatings, Heat Transfer Eng., 30 (2009) 1087-1095.

[2] X. Cao, R. Vassen, D. Stoever, Ceramic materials for thermal barrier coatings, J. Eur. Ceram. Soc., 24 (2004) 1-10.

[3] P. Baulista, Advances in gas turbine technology, Proceedings of the 7th cogeneration and independent power congress, natural gas purchasing'92, HVAC controls and energy conservation'92, 1992 indoor air quality congress, 1992.

[4] J.R. Nicholls, R.G. Wellman, R. Steenbakker, J. Feist, Self diagnostic EB-PVD thermal barrier coatings, Adv. Sci. Technol., 72 (2010) 65-74.

[5] M.D. Chambers, D.R. Clarke, Doped oxides for high-temperature luminescence and lifetime thermometry, Rev. Mater. Res., 39 (2009) 325-359.

[6] J.I. Eldridge, C.M. Spuckler, K.W. Street, J.R. Markham, Infrared radiative properties of yttria-stabilized zirconia thermal barrier coatings, 26th Annual Conf. Composites, Adv. Ceram., Mater., Struct.: B: Ceram. Eng. Sci. Proc., John Wiley \& Sons, Inc, 2002, pp. 417-430.

[7] K.-L. Choy, A.L. Heyes, J.P. Feist, Thermal barrier coating with thermoluminescent indicator material embedded therein, Google Patents, 2012.

[8] S. Alaruri, D. McFarland, A. Brewington, M. Thomas, N. Sallee, Development of a fiber-optic probe for thermographic phosphor measurements in turbine engines, Opt. Lasers Eng., 22 (1995) 17-31.

[9] S. Allison, G. Gillies, Remote thermometry with thermographic phosphors: instrumentation and applications, Rev. Sci. Instrum., 68 (1997) 2615-2650.

[10] C. Bird, J. Mutton, R. Shepherd, M. Smith, H. Watson, Surface temperature measurement in turbines, AGARD Conf. Proc., AGARD, 1998, pp. 21.24-21.10.

[11] M. Aldén, A. Omrane, M. Richter, G. Särner, Thermographic phosphors for thermometry: a survey of combustion applications, Prog. Energy Combust. Sci., 37 (2011) 422-461.

[12] D.R. Clarke, Embedded optical sensors for thermal barrier coatings, The Regents Of The University Of California, 2006. 
[13] R.m.J.L. Steenbakker, J.r.P. Feist, R.G. Wellman, J.R. Nicholls, Sensor thermal barrier coatings: remote in situ condition monitoring of EB-PVD coatings at elevated temperatures, J. Eng. Gas Turb. Power, 131 (2009) 041301.

[14] M.M. Gentleman, D.R. Clarke, Concepts for luminescence sensing of thermal barrier coatings, Surf. Coat. Technol., 188-189 (2004) 93-100.

[15] M.D. Chambers, D.R. Clarke, Effect of long term, high temperature aging on luminescence from Eu-doped YSZ thermal barrier coatings, Surf. Coat. Technol., 201 (2006) 3942-3946.

[16] X. Chen, Z. Mutasim, J. Price, J. Feist, A. Heyes, S. Seefeldt, Industrial sensor TBCs: Studies on temperature detection and durability, Int. J. Appl. Ceram. Technol., 2 (2005) 414-421.

[17] D. Peng, L. Yang, T. Cai, Y. Liu, X. Zhao, Z. Yao, Phosphor-doped thermal barrier coatings deposited by air plasma spray for in-depth temperature sensing, Sens., 16 (2016) 1490.

[18] P.Y. Sollazzo, J.P. Feist, S. Berthier, B. Charnley, J. Wells, A.L. Heyes, Application of a production line phosphorescence sensor coating system on a jet engine for surface temperature detection, DOI 10.1063/1.4819663(2013) 897-902.

[19] J.P. Feist, P.Y. Sollazzo, S. Berthier, B. Charnley, J. Wells, Application of an Industrial Sensor Coating System on a Rolls-Royce Jet Engine for Temperature Detection, J. Eng. Gas Turb. Power, 135 (2012) 012101.

[20] A.L. Heyes, J.P. Feist, X. Chen, Z. Mutasim, J.R. Nicholls, Optical nondestructive condition monitoring of thermal barrier coatings, J. Eng. Gas Turb. Power, 130 (2008) 061301.

[21] F.A. Nada, A. Lantz, J. Larfeldt, N. Markocsan, M. Aldén, M. Richter, Remote temperature sensing on and beneath atmospheric plasma sprayed thermal barrier coatings using thermographic phosphors, Surf. Coat. Technol., 302 (2016) 359-367.

[22] J.I. Eldridge, C.M. Spuckler, Determination of scattering and absorption coefficients for plasma-sprayed yttria-stabilized zirconia thermal barrier coatings, J. Am. Ceram. Soc., 91 (2008) 1603-1611.

[23] S.W. Allison, D. Moore, G. Gillies, A. Heyes, J. Nicholls, U. Cranfield, Spectral properties of Dy-doped thermal barrier sensor coatings, ISA, 55 th Int. Instru. Symp., 2009.

[24] Y. Shen, M.D. Chambers, D.R. Clarke, Effects of dopants and excitation wavelength on the temperature sensing of Ln3+-doped 7YSZ, Surf. Coat. Technol., 203 (2008) 456-460.

[25] M.M. Gentleman, High temperature sensing of thermal barrier materials by luminescence[M] ProQuest, DOI (2006).

[26] Z Zou, C Xing, F Guo, X Zhao, P. Xiao, A novel strain-tolerant thermal barrier coating sprayed by zirconia powder with unique microstructure, Scripta Mater. submitted to Scripta Mater., DOI (2016).

[27] J. Liao, D. Zhou, B. Yang, R. Liu, Q. Zhang, Sol-gel preparation and photoluminescence properties of tetragonal ZrO 2: Y 3+, Eu 3+ nanophosphors, Opt. Mater., 35 (2012) 274-279.

[28] A. Speghini, M. Bettinelli, P. Riello, S. Bucella, A. Benedetti, Preparation, structural characterization, and luminescence properties of Eu 3+-doped nanocrystalline $\mathrm{ZrO}$ 2, J. Mater. Res., 20 (2005) 2780-2791.

[29] J. Brübach, J. Feist, A. Dreizler, Characterization of manganese-activated magnesium fluorogermanate with regards to thermographic phosphor thermometry, Meas. Sci. Technol., 19 (2008) 025602.

[30] J. Brübach, J. Janicka, A. Dreizler, An algorithm for the characterisation of multi-exponential decay curves, Opt. Lasers Eng., 47 (2009) 75-79.

[31] K. C, L. J, A.N. F, R. M, A. M, Investigation and compensation of the nonlinear response in 
photomultiplier tubes for quantitative single-shot measurements, Rev. Sci. Instrum., 83 (2012) 034901. [32] J. Brübach, J. Zetterberg, A. Omrane, Z. Li, M. Aldén, A. Dreizler, Determination of surface normal temperature gradients using thermographic phosphors and filtered Rayleigh scattering, Appl. Phys. B, 84 (2006) 537-541.

[33] Y. Hui, Y. Zhao, S. Zhao, L. Gu, X. Fan, L. Zhu, B. Zou, Y. Wang, X. Cao, Fluorescence of Eu3+ as a probe of phase transformation of zirconia, J. Alloys Compd., 573 (2013) 177-181.

[34] J.P. Feist, Development of phosphor thermometry for gas turbines, University of London, 2001.

[35] A.H. Khalid, K. Kontis, Thermographic phosphors for high temperature measurements: principles, current state of the art and recent applications, Sens., 8 (2008) 5673-5744.

[36] J.I. Eldridge, C.M. Spuckler, J.R. Markham, Determination of scattering and absorption coefficients for plasma-sprayed yttria-stabilized zirconia thermal barrier coatings at elevated temperatures, J. Am. Ceram. Soc., 92 (2009) 2276-2285.

[37] G.Y. Yang, C.Y. Zhao, A Comparative Experimental Study on Radiative Properties of EB-PVD and Air Plasma Sprayed Thermal Barrier Coatings, J. Heat Transf. (Trans. ASME), 137 (2015) 091024. [38] G.Y. Yang, C.Y. Zhao, B.X. Wang, Experimental study on radiative properties of air plasma sprayed thermal barrier coatings, Int. J. Heat Mass Transf., 66 (2013) 695-698.

[39] J.I. Eldridge, T.J. Bencic, C.M. Spuckler, J. Singh, D.E. Wolfe, Delamination-indicating thermal barrier coatings using YSZ:Eu sublayers, J. Am. Ceram. Soc., 89 (2006) 3246-3251.

[40] D. Liu, O. Lord, O. Stevens, P.E.J. Flewitt, The role of beam dispersion in Raman and photo-stimulated luminescence piezo-spectroscopy of yttria-stabilized zirconia in multi-layered coatings, Acta Mater., 61 (2013) 12-21.

[41] N.G. Petrik, D.P. Taylor, T.M. Orlando, Laser-stimulated luminescence of yttria-stabilized cubic zirconia crystals, J. Appl. Phys., 85 (1999) 6770-6776.

[42] S. Paje, J. Llopis, Luminescence of polycrystalline cubic and tetragonal yttria-stabilized zirconia, J. Phys. Chem. Solids, 55 (1994) 671-676. 


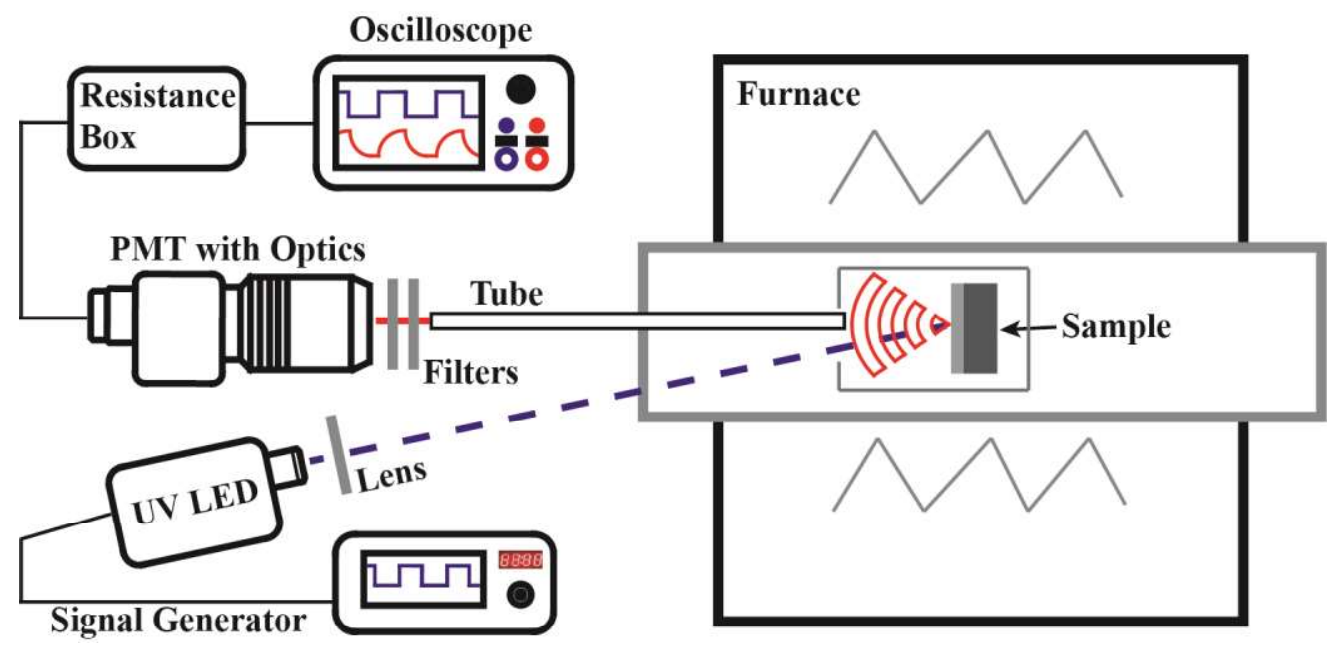

Figure 1 Schematic of the experimental set up used to investigate the decay lifetime and intensity of the selected sensor TBCs. For an observation of the luminescence spectra, the PMT with optics was replaced by a grating spectrometer with a photodiode array housed in a personal computer and triggered by the laser. 


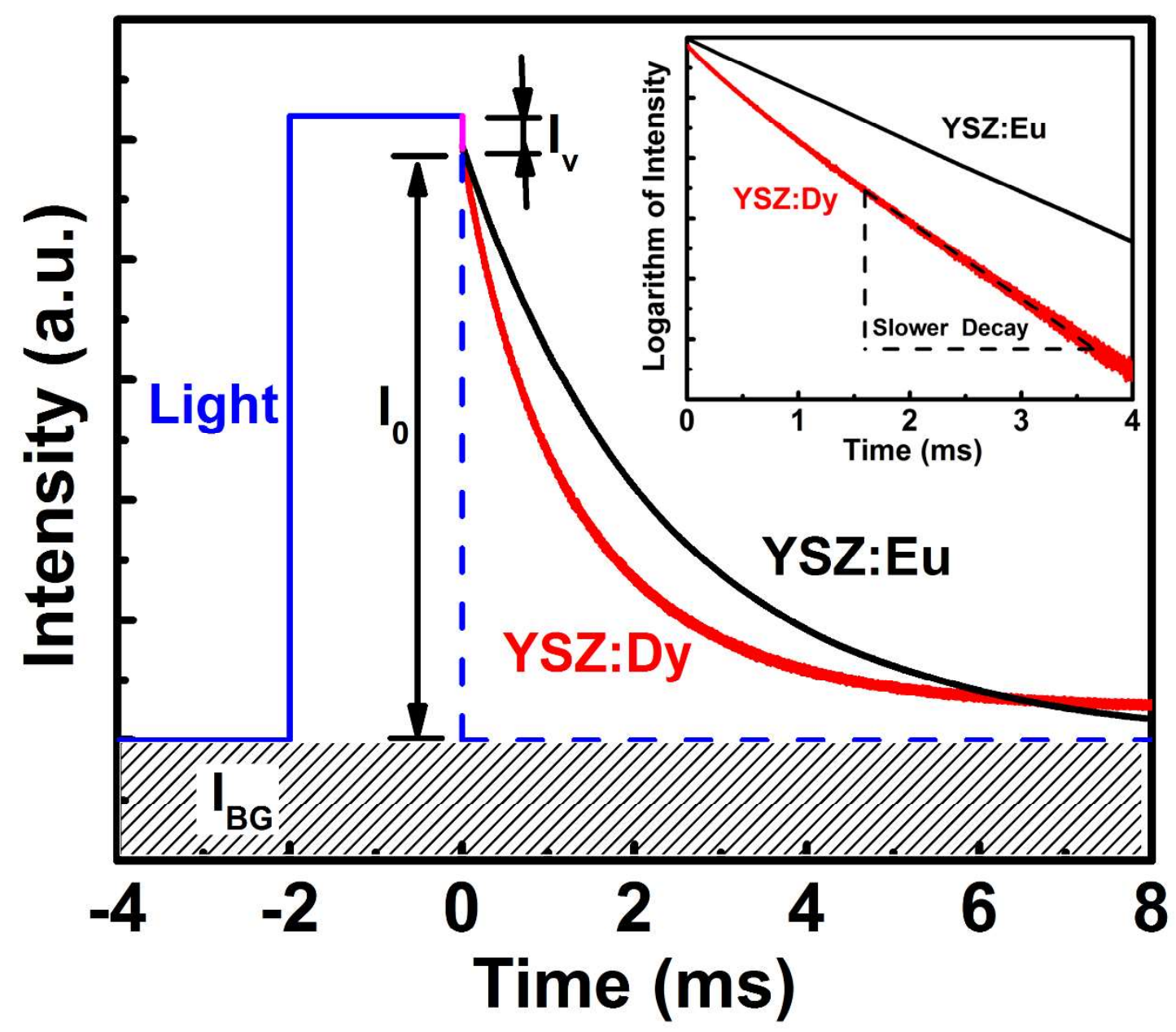

Figure 2 Schematic of an excitation pulse (in blue) and sample decay curve of YSZ:Eu (in black) and YSZ:Dy (in red) specimens recorded by the oscilloscope, where $I_{\mathrm{BG}}$ is the background level (in shaded area), $I_{\mathrm{v}}$ is the intensity of the vertical decay at $t=0$ and $I_{0}$ is the intensity at the start of the YSZ:Eu and YSZ:Dy luminescence decay. The inset shows the curves of logarithm of intensity with time. 


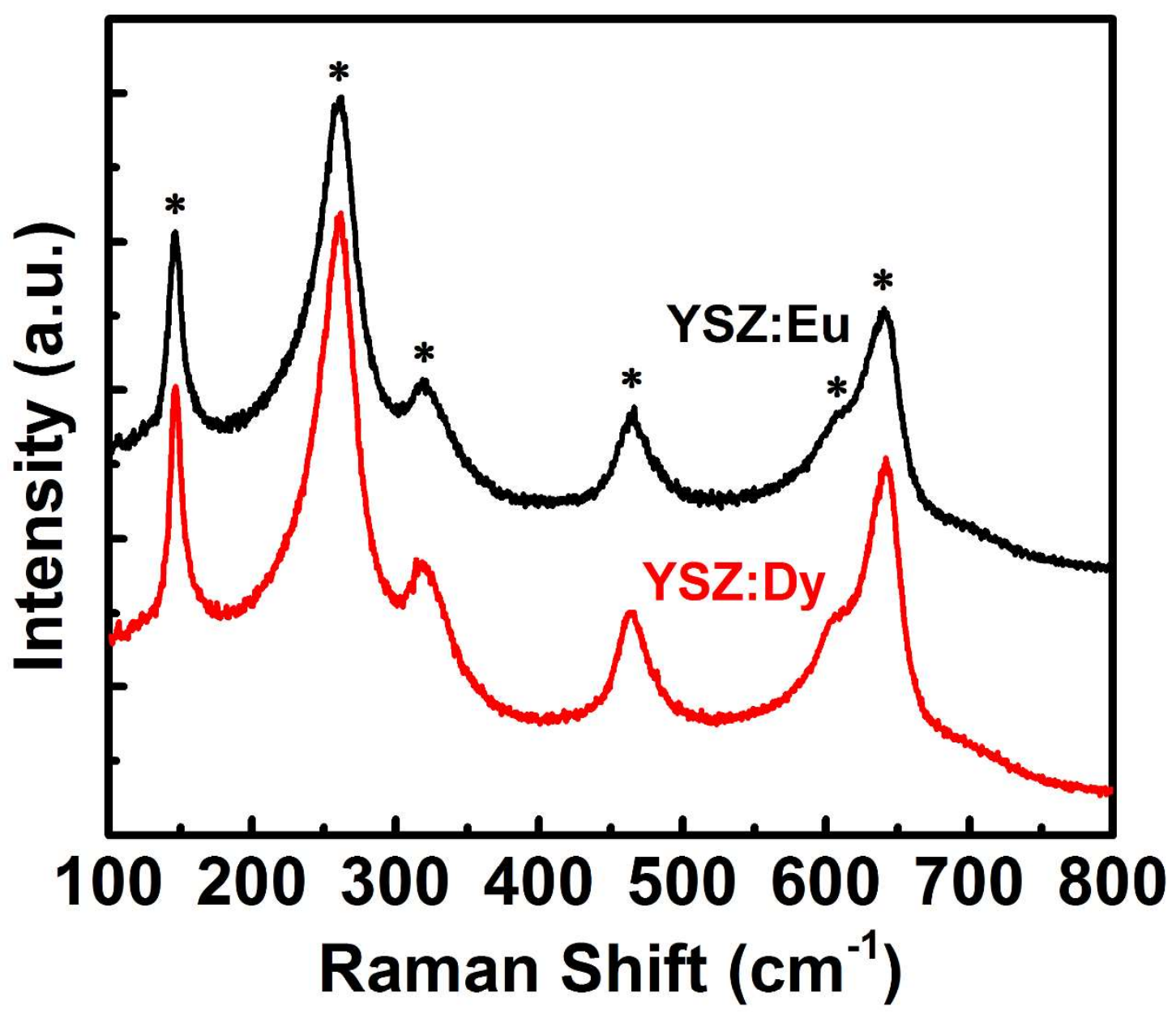

Figure 3 Raman spectra of the YSZ:Eu and YSZ:Dy powder. The patterns corresponding to the tetragonal phases, as indicated by the * symbols. 

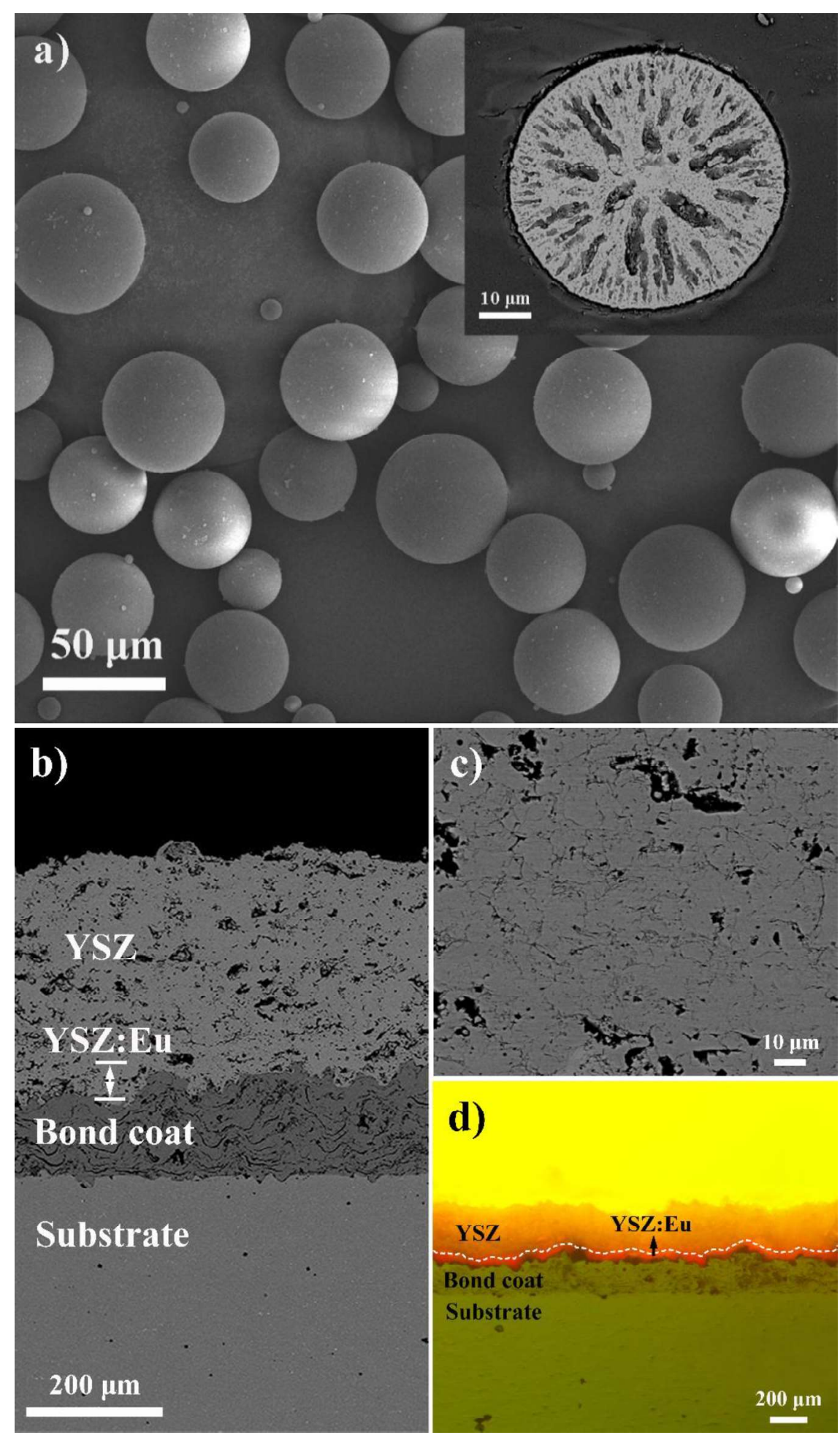

Figure 4 (a) SEM images of the surface and cross-section morphology (inset) of luminescence hollow spheres after granulation; (b) Cross-sectional SEM image of the sensor TBCs with an approximately $40 \mu \mathrm{m}$-thick YSZ:Eu sensor coating at the base of the ceramic coating and an undoped YSZ coating on top approximately $280 \mu \mathrm{m}$ thick after deposition; c) Enlarge SEM image of the APS YSZ topcoat; d) Luminescence optical image of the sensor TBCs. 


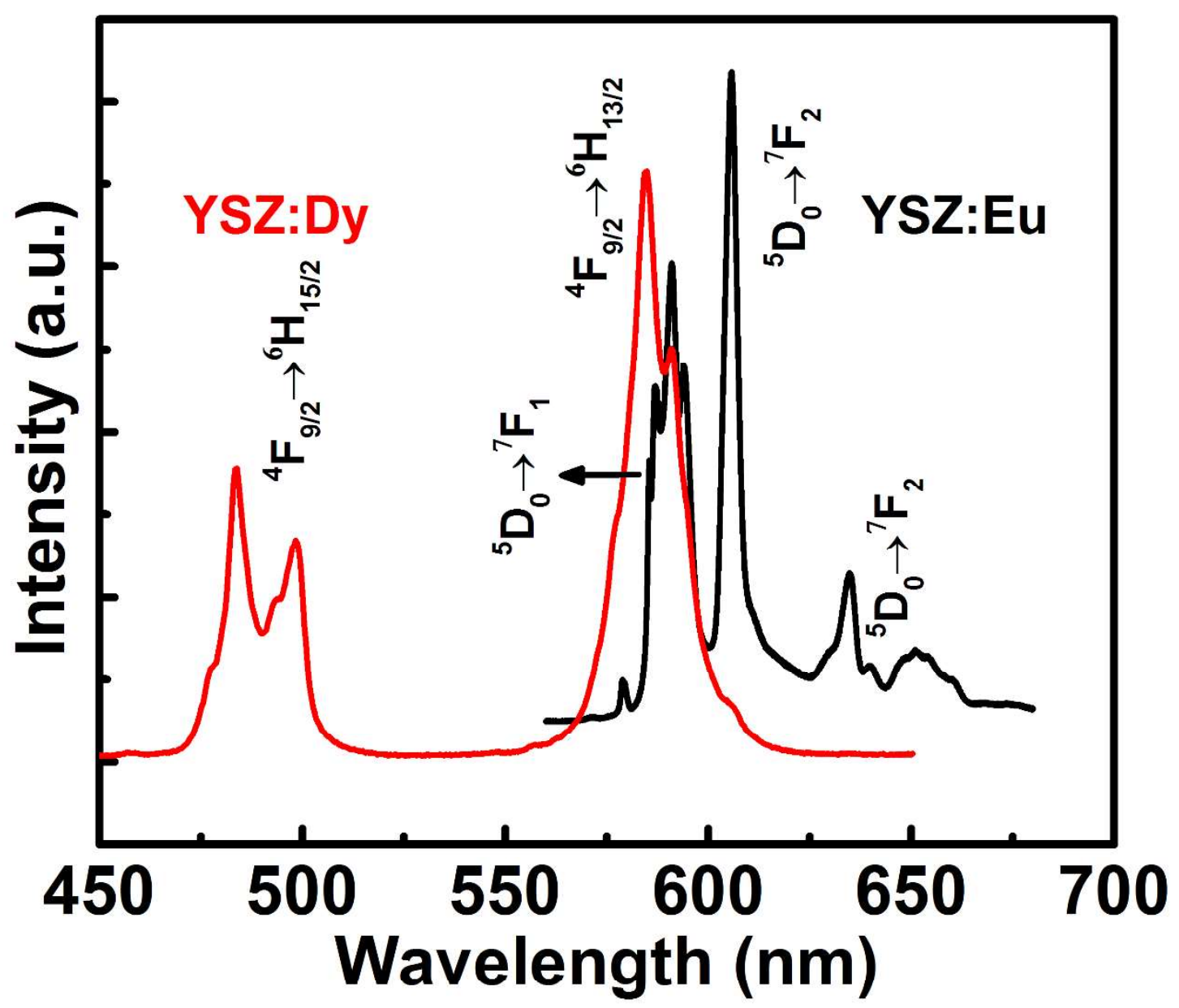

Figure 5 Luminescence spectra of the typical powder specimens of YSZ:Eu (in black) and YSZ:Dy (in red) excited at $405 \mathrm{~nm}$. 

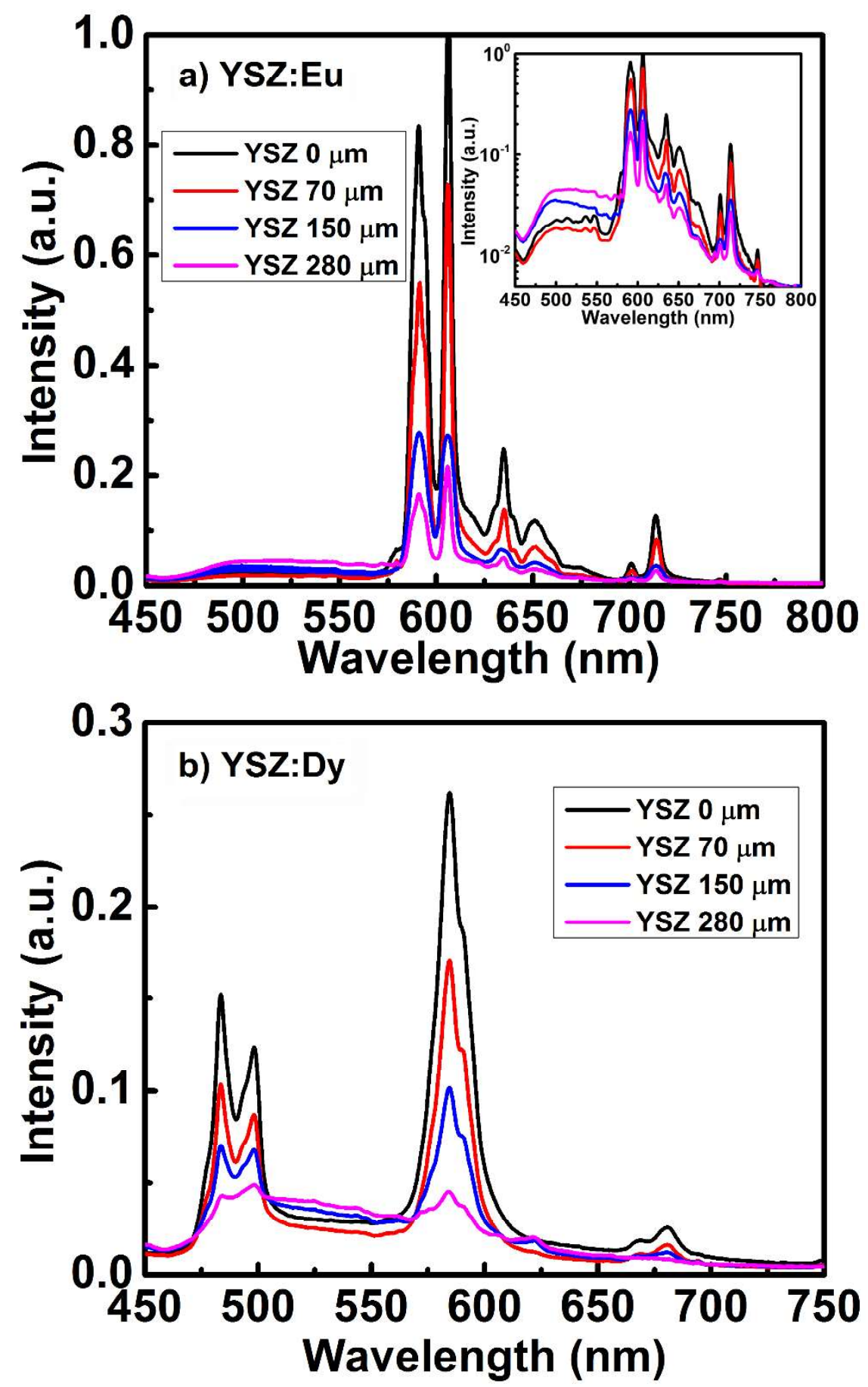

Figure 6 Luminescence spectra of (a) the YSZ:Eu and (b) YSZ:Dy TBCs specimens and the spectral information of APS sensor TBCs with different topcoat thickness obtained after the luminescence intensity of YSZ is stabilized. The luminescence spectra of YSZ:Eu specimens are also plotted on a logarithmic scale (inset). 

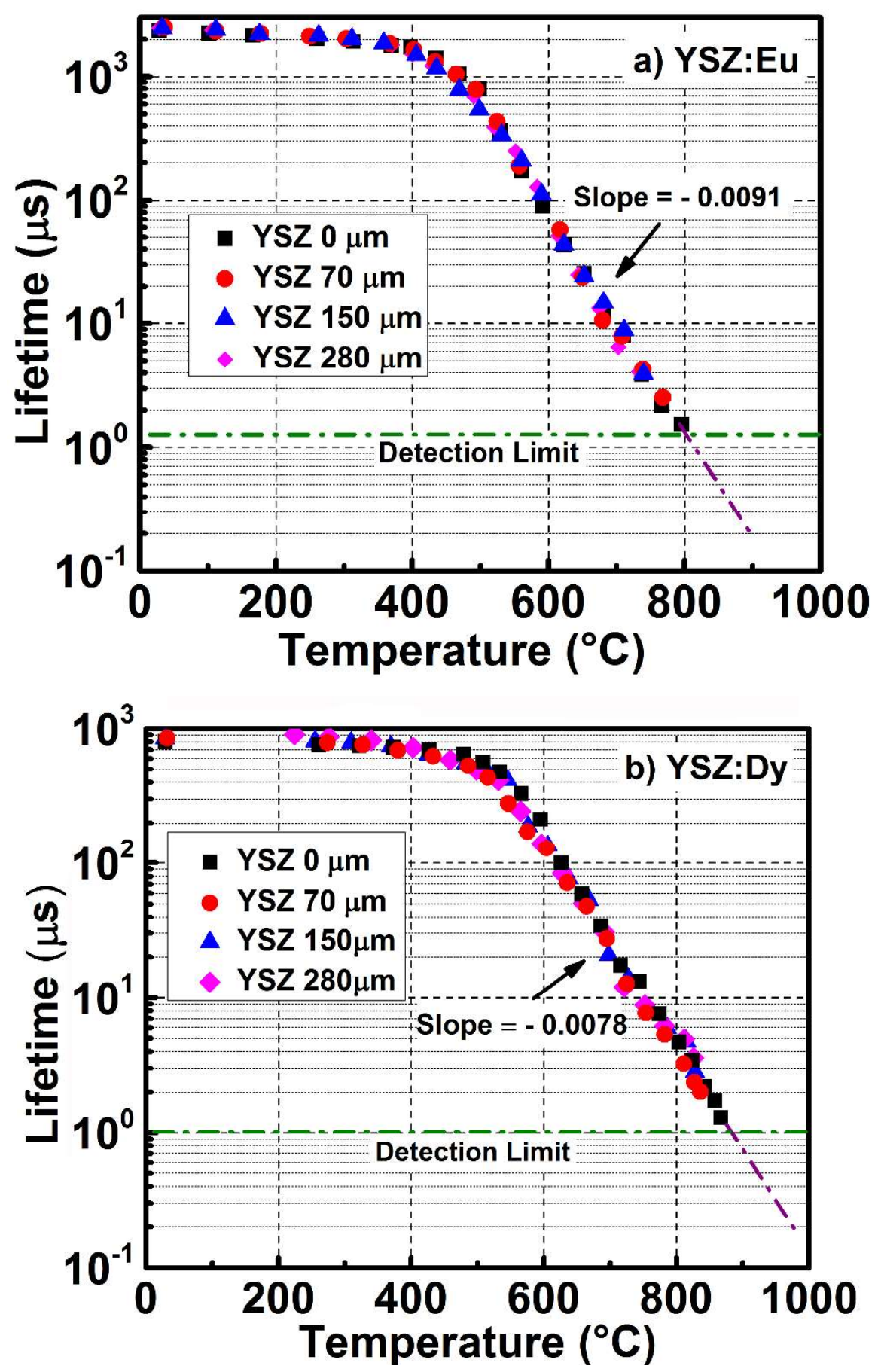

Figure 7 Lifetime decay-temperature curves for (a) YSZ:Eu and (b) YSZ:Dy specimens with four different thicknesses of YSZ topcoat. 

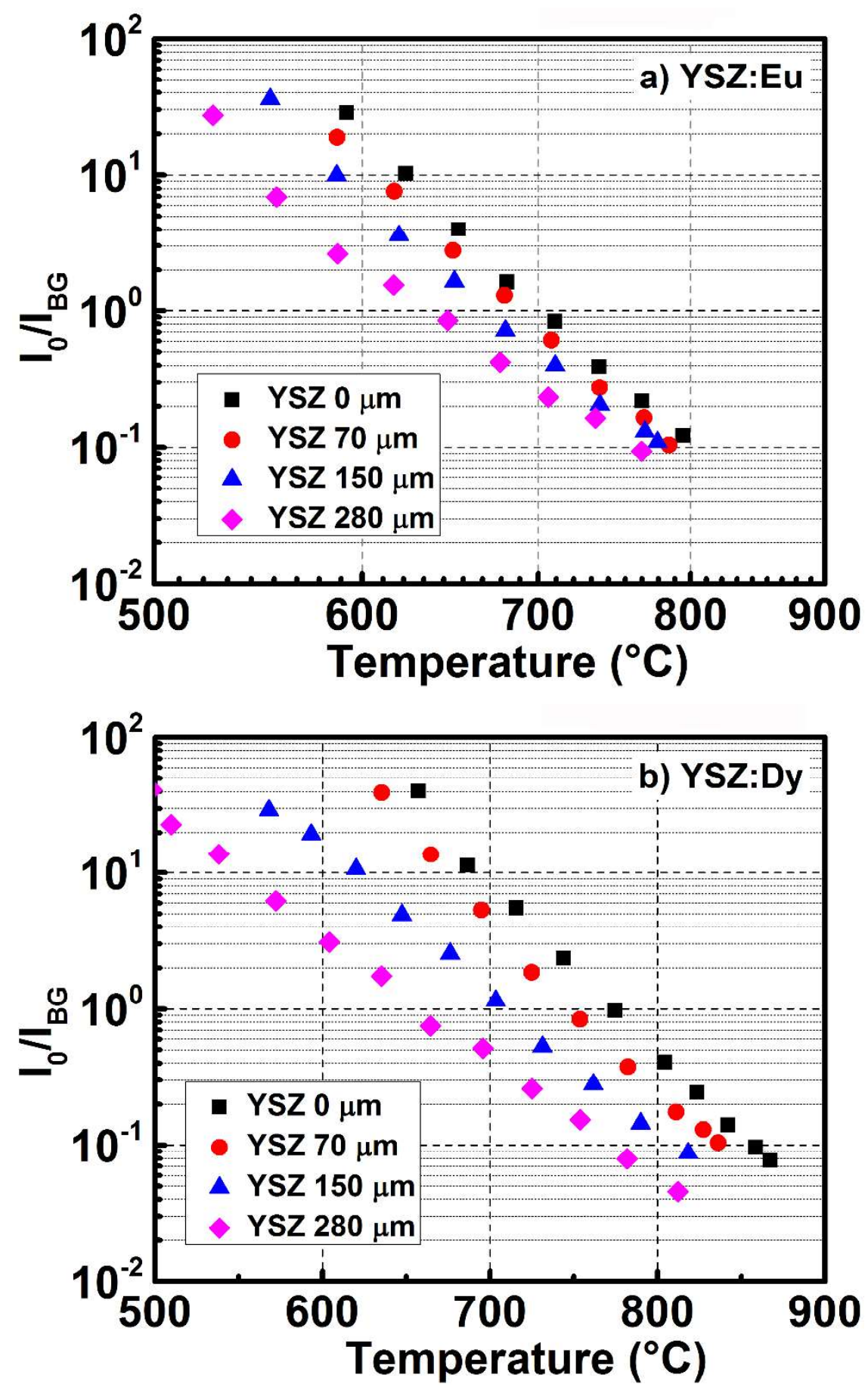

Figure 8 The relations between the temperature and SBR, $I_{0} / I_{\mathrm{BG}}$, of $\mathrm{YSZ}: \mathrm{Eu}$ and YSZ:Dy specimens with four different thicknesses of YSZ topcoat. 


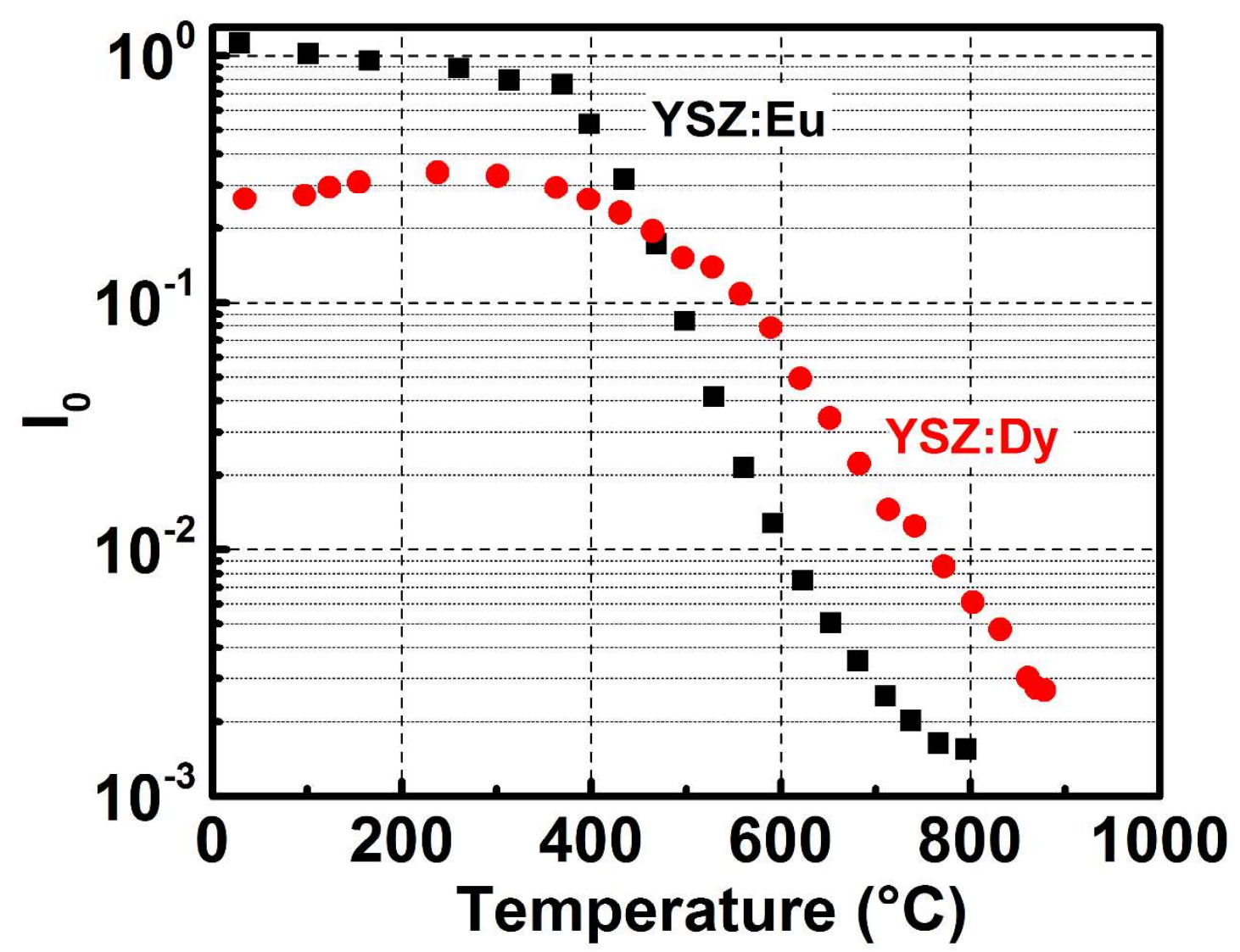

Figure 9 Temperature dependence of the luminescence intensities, $I_{0}$, of the YSZ:Eu (in black) and YSZ:Dy (in red). 


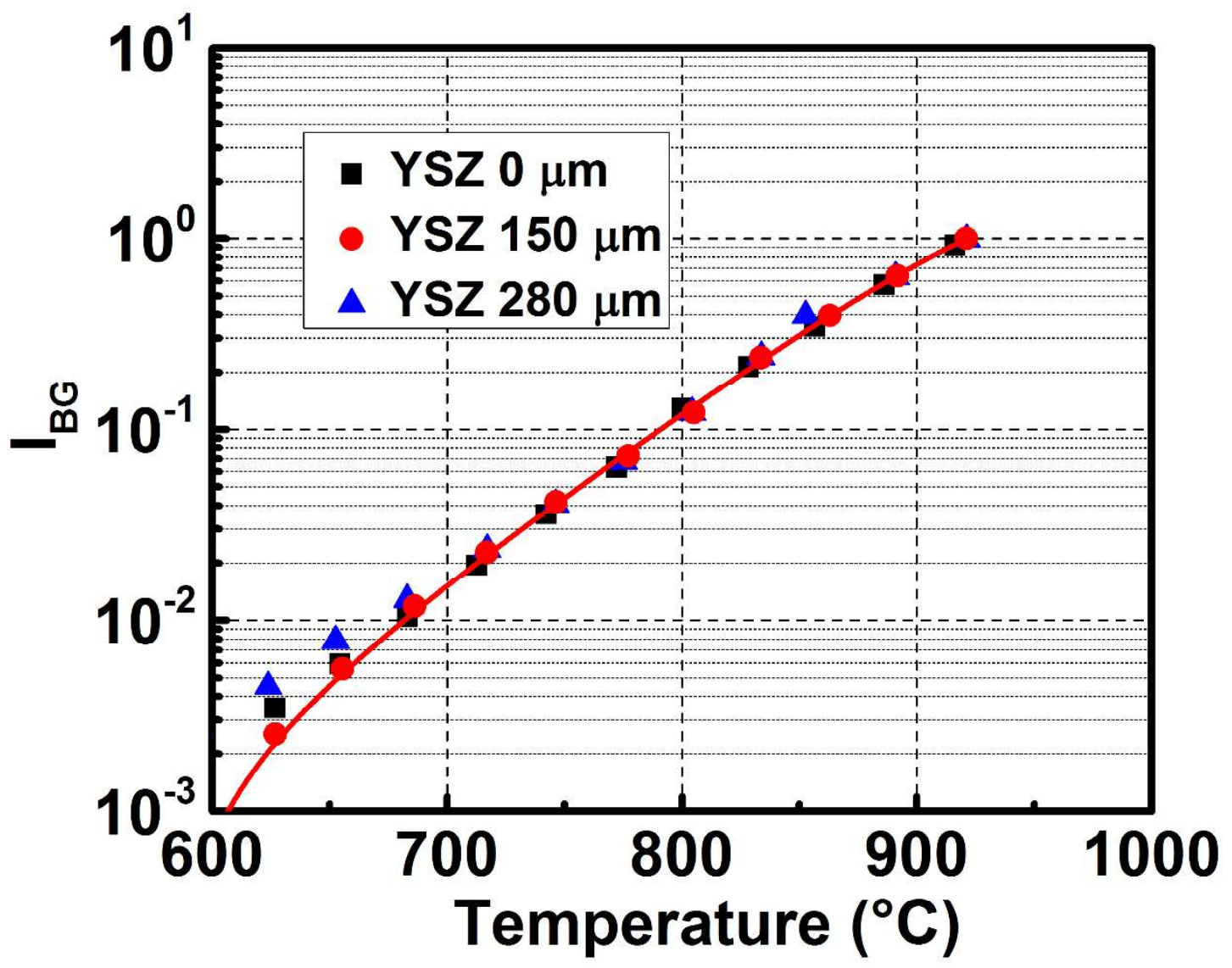

Figure 10 Normalized background thermal radiations of YSZ:Eu specimens with different YSZ topcoat thickness as a function of temperature. 

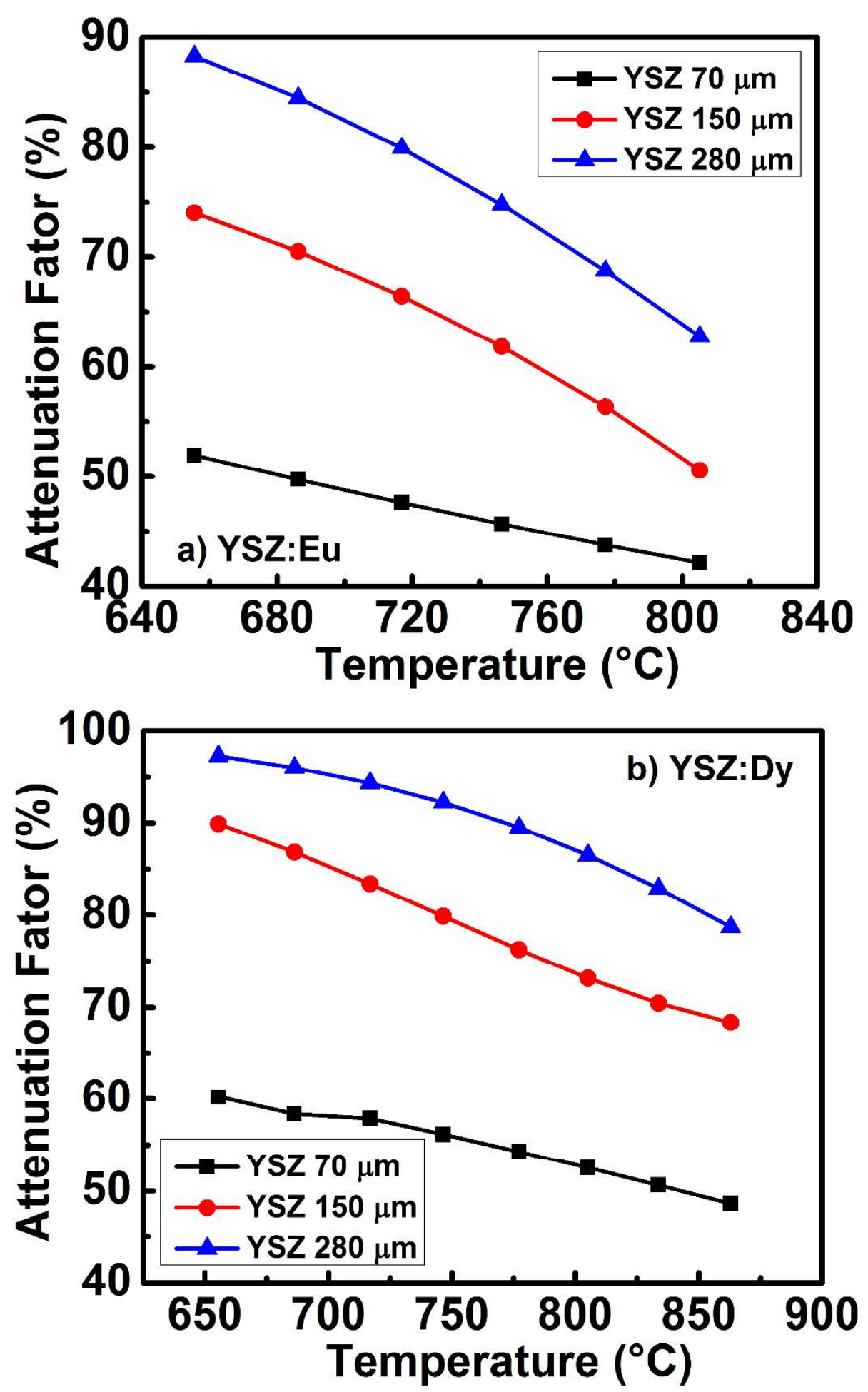

Fig.11 Calculated attenuation factors with different YSZ topcoat thickness as a function of temperature for (a) YSZ:Eu and (b) YSZ:Dy specimens. 


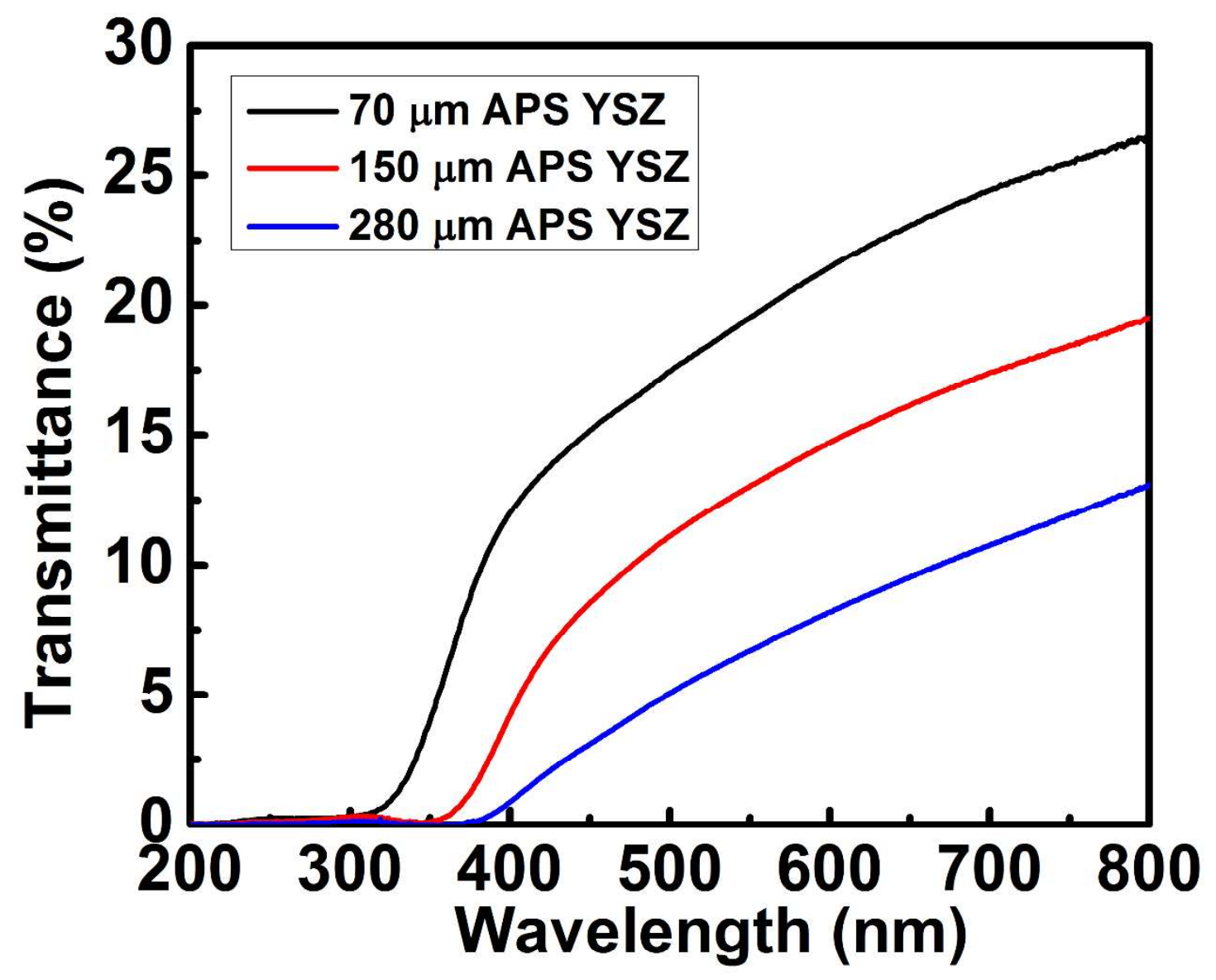

Figure 12 Transmittance for APS 8 wt $\%$ YSZ topcoat with thicknesses of 70, 150 and $280 \mu \mathrm{m}$ at room temperature. 

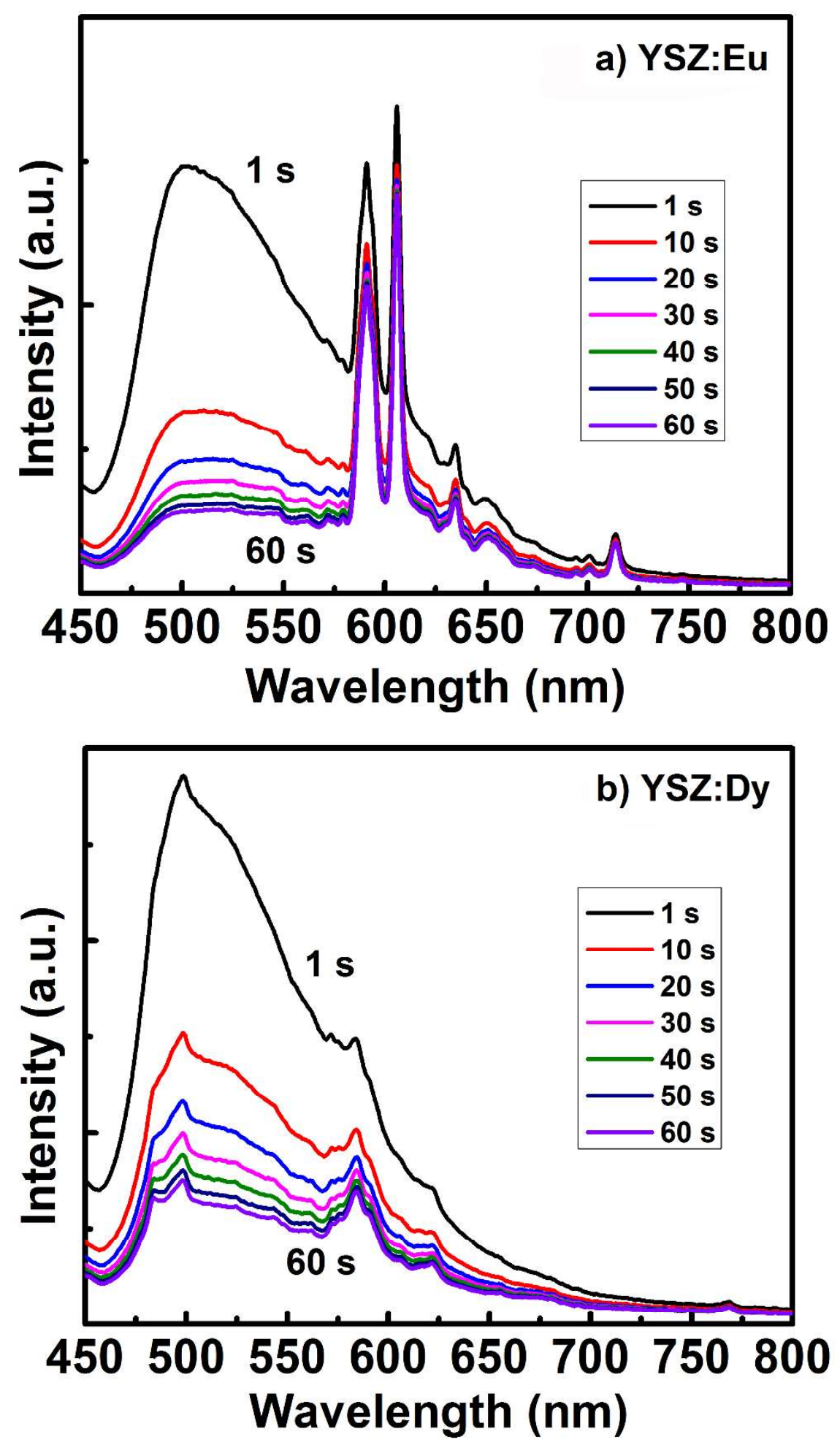

Figure A.1 Time dependent luminescence spectra of (a) the YSZ:Eu and (b) YSZ:Dy TBCs specimens. 


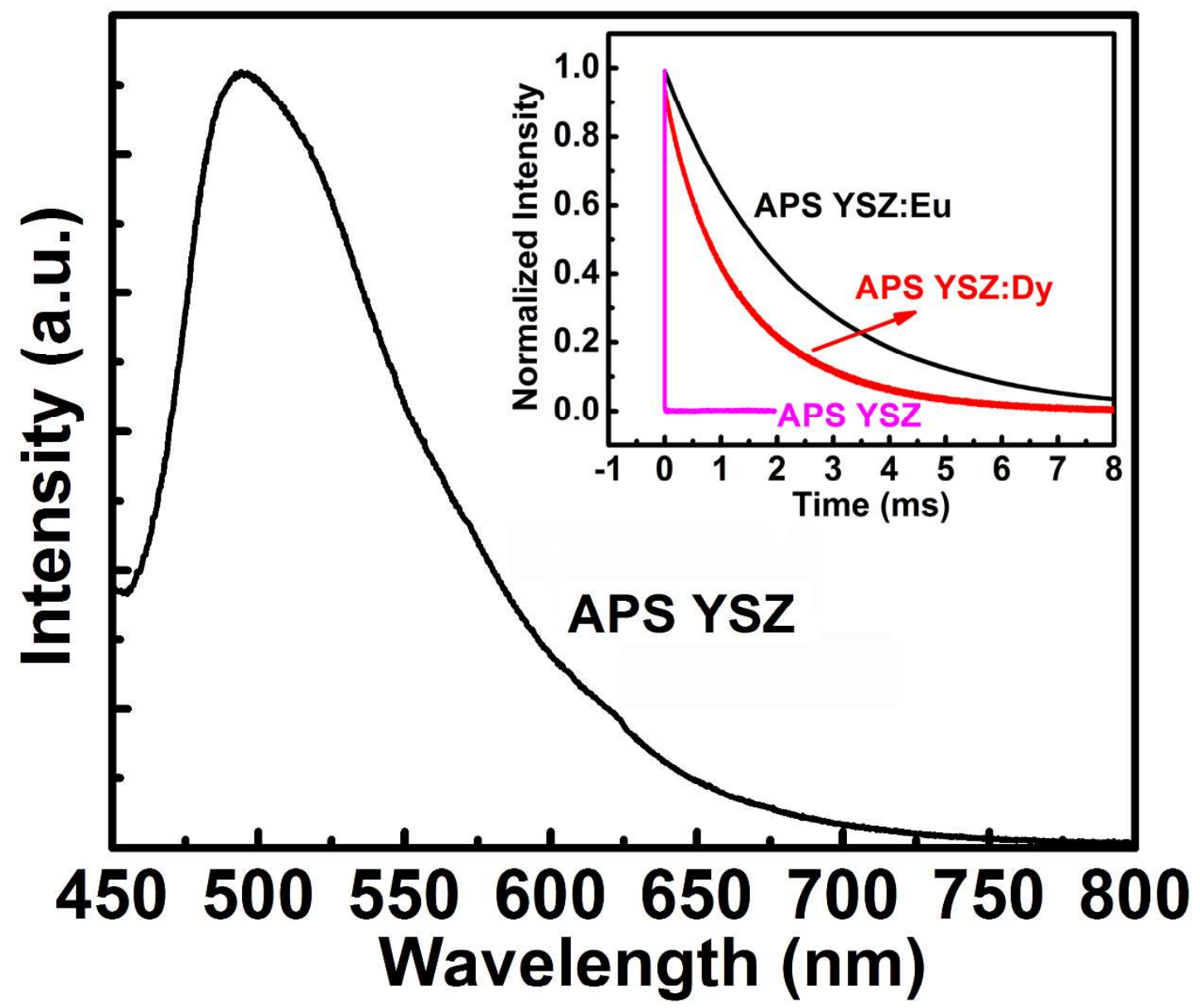

Figure A.2 Luminescence spectrum, and decay curve of the YSZ topcoat compared with that of the YSZ:Eu and YSZ:Dy specimens after normalized by $I_{0}$ (inset). 
Table 1. Air plasma spray parameters for bond coat and ceramic coatings (sensor coating and YSZ top coat) powder deposition

\begin{tabular}{ccc}
\hline Spray parameters & Bond Coat & YSZ/sensor coating \\
\hline Spray distance (mm) & 100 & 90 \\
Arc current (A) & 400 & 420 \\
Voltage (V) & 144 & 148 \\
Ar flow rate (SLPM) & 91.5 & 110 \\
H $_{2}$ flow rate (SLPM) & 15.9 & 20 \\
Carrier gas flow rate (SLPM) & 300 & 300 \\
Gun speed (mm/s) & 800 & 500 \\
\hline
\end{tabular}

SLPM=Standard litres per minute 


\section{List of figure captions}

Figure 1 Schematic of the experimental set up used to investigate the decay lifetime and intensity of the selected sensor TBCs. For an observation of the luminescence spectra, the PMT with optics was replaced by a grating spectrometer with a photodiode array housed in a personal computer and triggered by the laser.

Figure 2 Schematic of an excitation pulse (in blue) and sample decay curve of YSZ:Eu (in black) and YSZ:Dy (in red) specimens recorded by the oscilloscope, where $I_{\mathrm{BG}}$ is the background level (in shaded area), $I_{\mathrm{v}}$ is the intensity of the vertical decay at $t=0$ and $I_{0}$ is the intensity at the start of the YSZ:Eu and YSZ:Dy luminescence decay. The inset shows the curves of logarithm of intensity with time.

Figure 3 Raman spectra of the YSZ:Eu and YSZ:Dy powder. The patterns corresponding to the tetragonal phases, as indicated by the * symbols.

Figure 4 (a) SEM images of the surface and cross-section morphology (inset) of luminescence hollow spheres after granulation; (b) Cross-sectional SEM image of the sensor TBCs with an approximately $40 \mu \mathrm{m}$-thick YSZ:Eu sensor coating at the base of the ceramic coating and an undoped YSZ coating on top approximately $280 \mu \mathrm{m}$ thick after deposition; c) Enlarge SEM image of the APS YSZ topcoat; d)

\section{Luminescence optical image of the sensor TBCs.}

Figure 5 Luminescence spectra of the typical powder specimens of YSZ:Eu (in black) and YSZ:Dy (in red) excited at $405 \mathrm{~nm}$.

Figure 6 Luminescence spectra of (a) the YSZ:Eu and (b) YSZ:Dy TBCs specimens and the spectral information of APS sensor TBCs with different topcoat thickness obtained after the luminescence intensity of YSZ is stabilized. The luminescence spectra of YSZ:Eu specimens are also plotted on a logarithmic scale (inset).

Figure 7 Lifetime decay-temperature curves for (a) YSZ:Eu and (b) YSZ:Dy specimens with four different thicknesses of YSZ topcoat.

Figure 8 The relations between the temperature and SBR, $I_{0} / I_{\mathrm{BG}}$, of $\mathrm{YSZ}: \mathrm{Eu}$ and YSZ:Dy specimens with four different thicknesses of YSZ topcoat. 
Figure 9 Temperature dependence of the luminescence intensities, $I_{0}$, of the YSZ:Eu (in black) and YSZ:Dy (in red).

Figure 10 Normalized background thermal radiations of YSZ:Eu specimens with different YSZ topcoat thickness as a function of temperature.

Figure 11 Calculated attenuation factors with different YSZ topcoat thickness as a function of temperature for (a) YSZ:Eu and (b) YSZ:Dy specimens.

Figure 12 Transmittance for APS $8 \mathrm{wt} \%$ YSZ topcoat with thicknesses of 70, 150 and $280 \mu \mathrm{m}$ at room temperature.

Figure A.1 Time dependent luminescence spectra of (a) the YSZ:Eu and (b) YSZ:Dy TBCs specimens.

Figure A.2 Luminescence spectrum, and decay curve of the YSZ topcoat compared with that of the YSZ:Eu and YSZ:Dy specimens after normalized by $I_{0}$ (inset). 


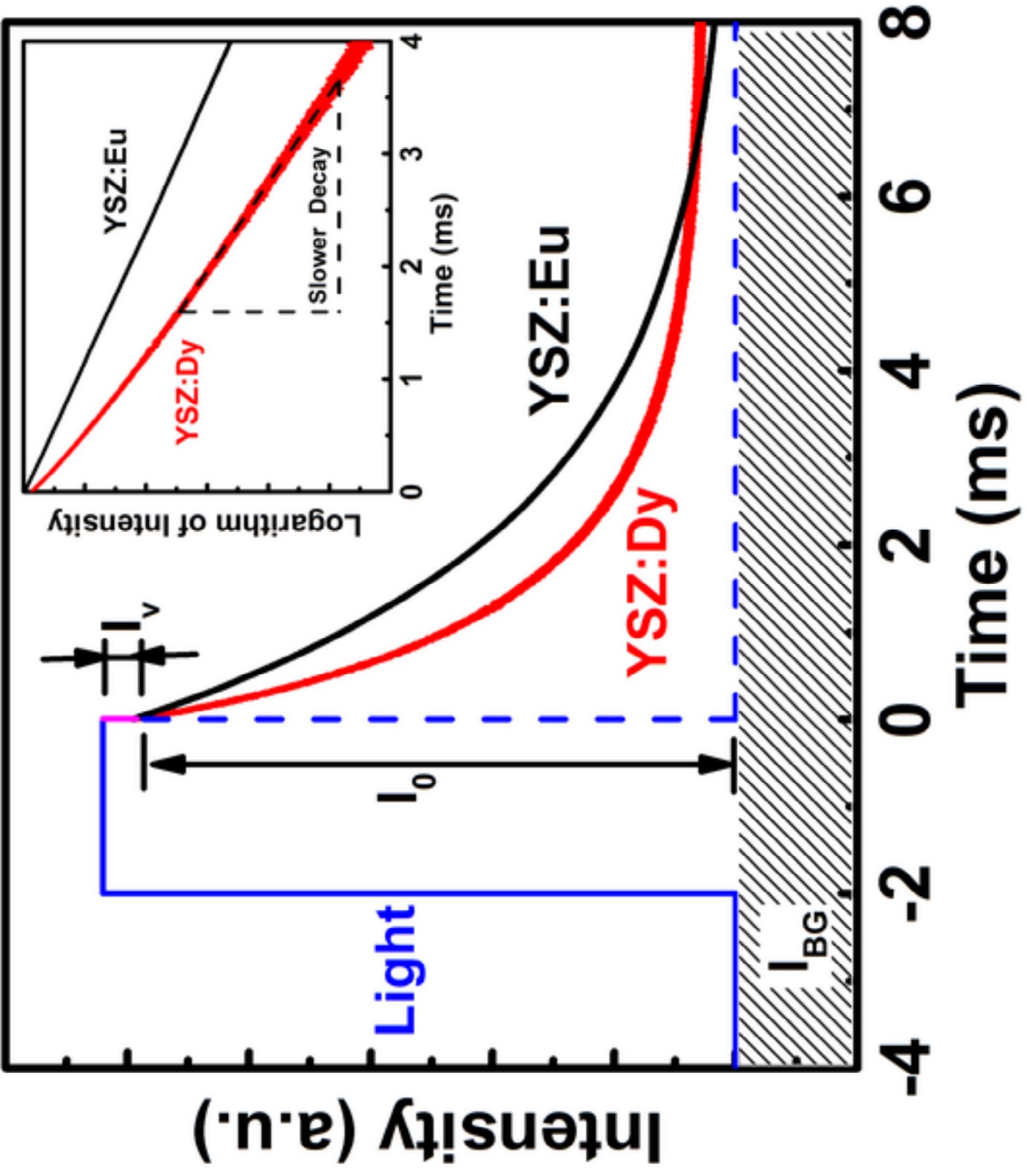




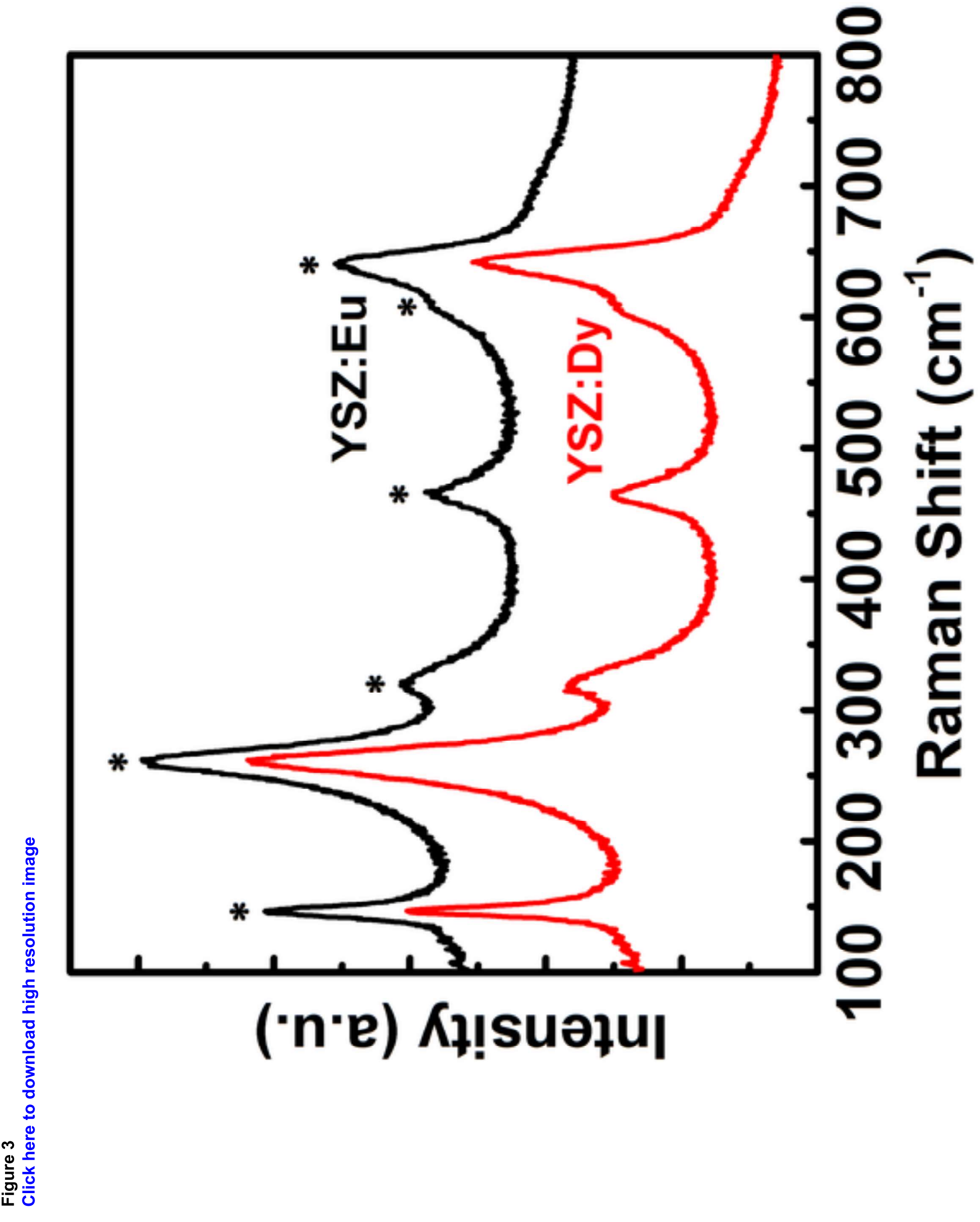




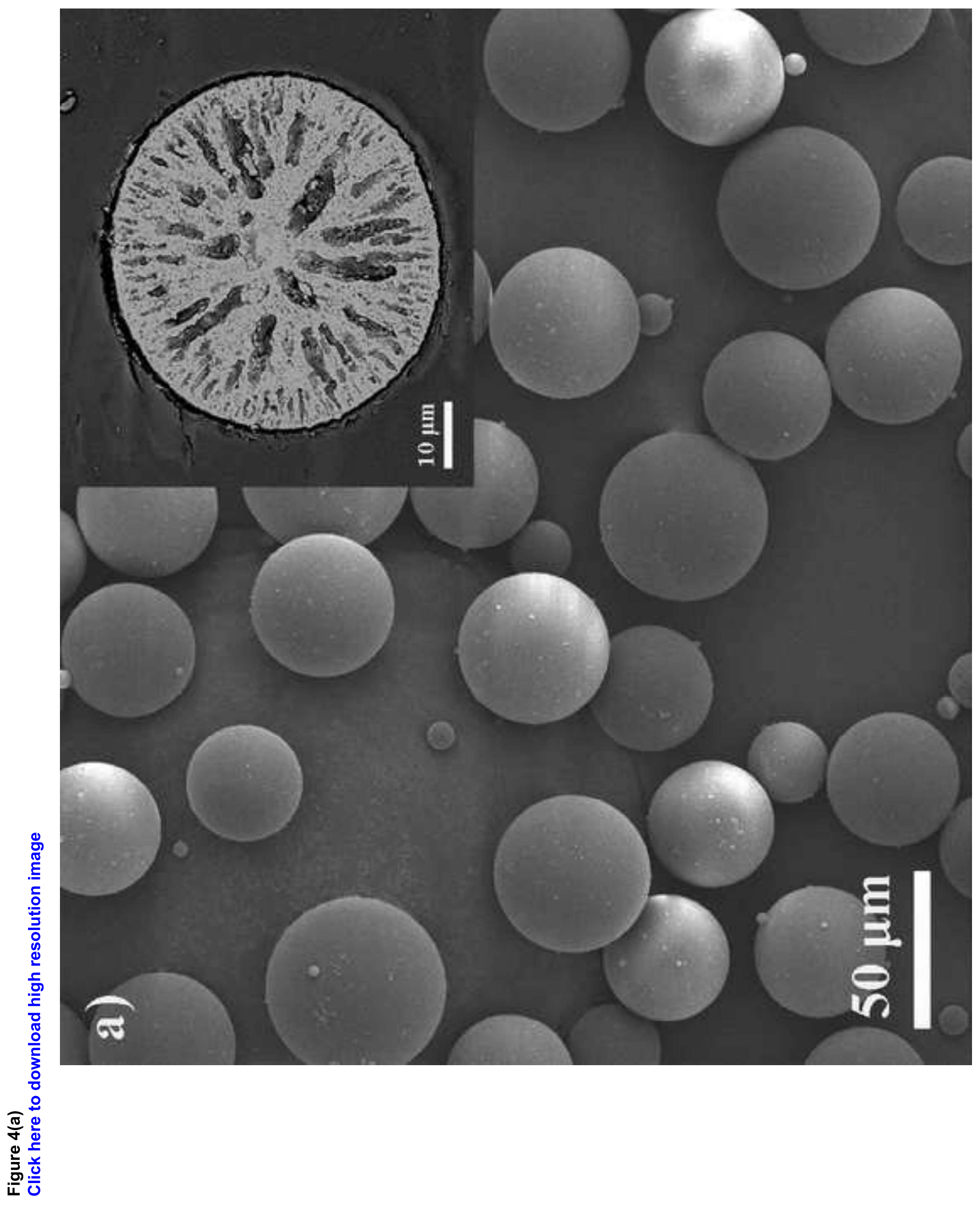



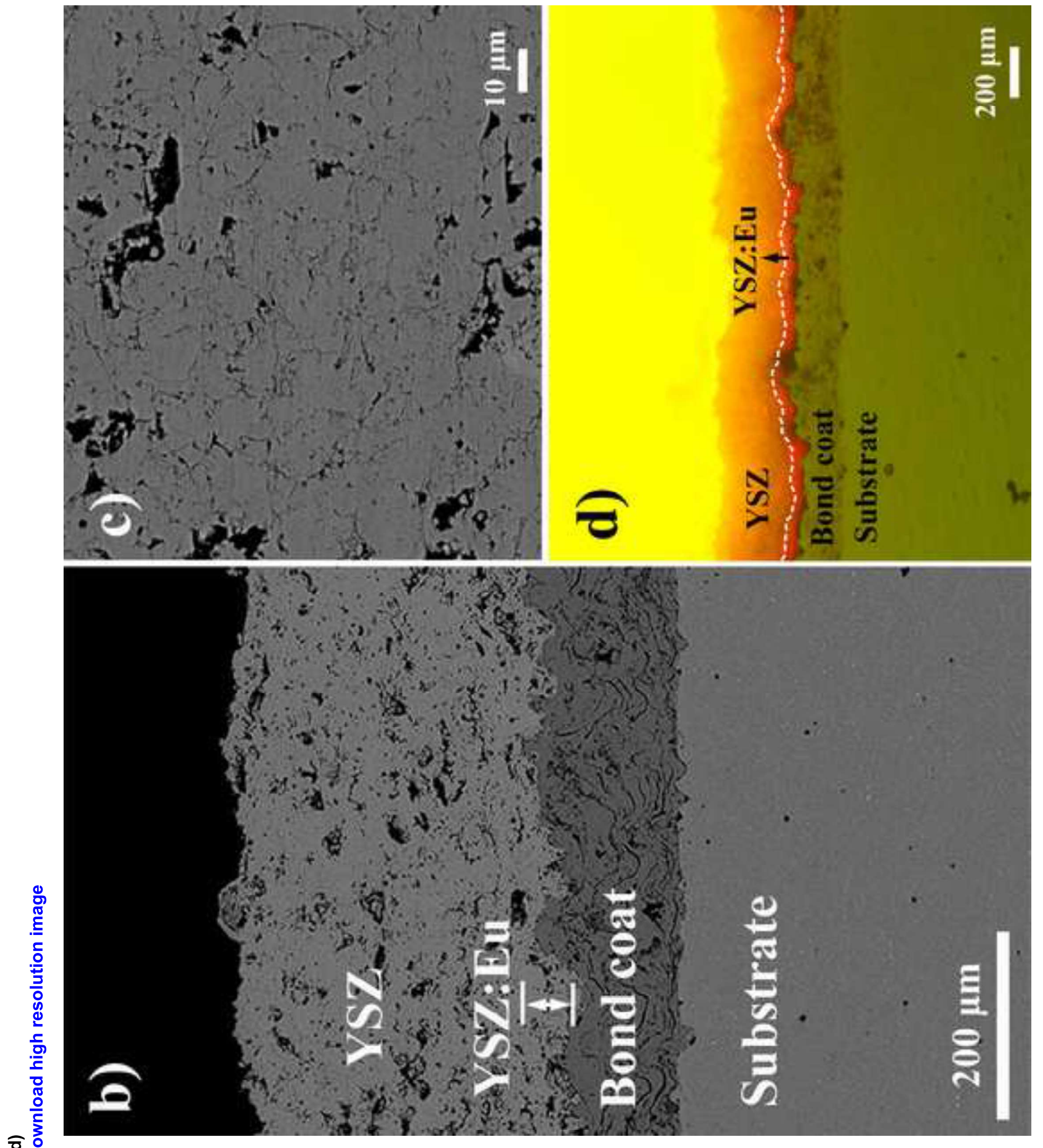

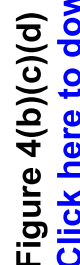




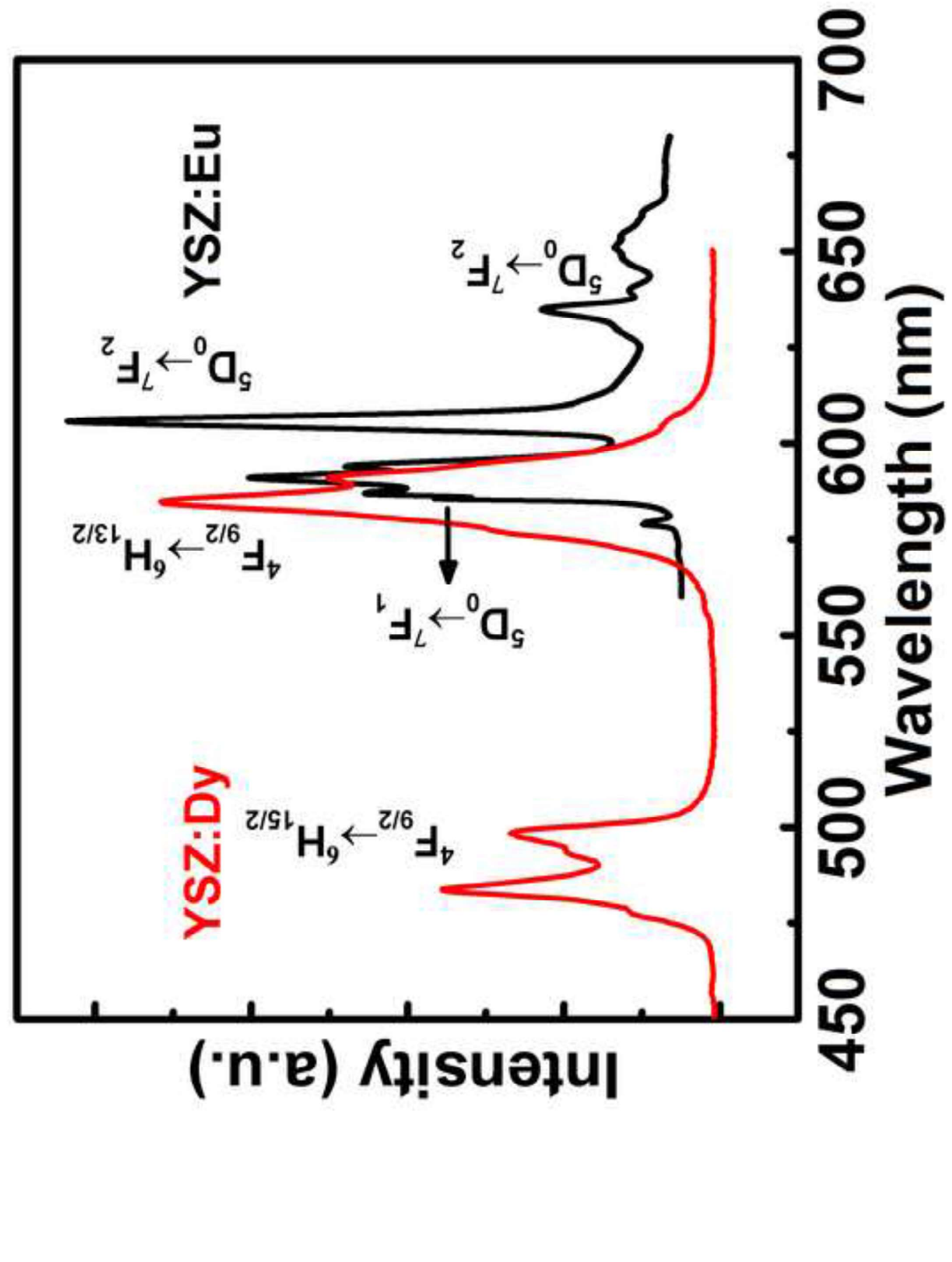




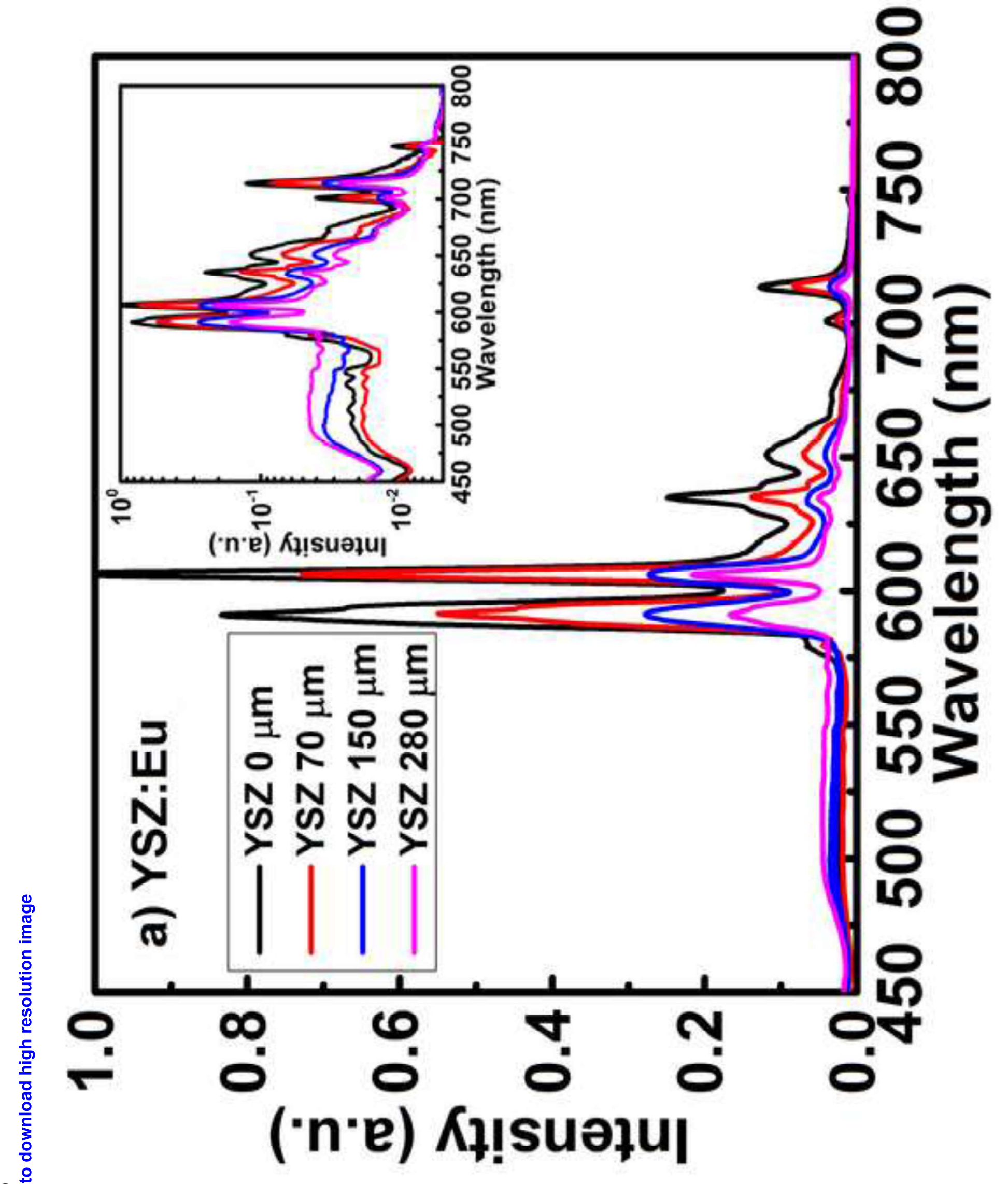




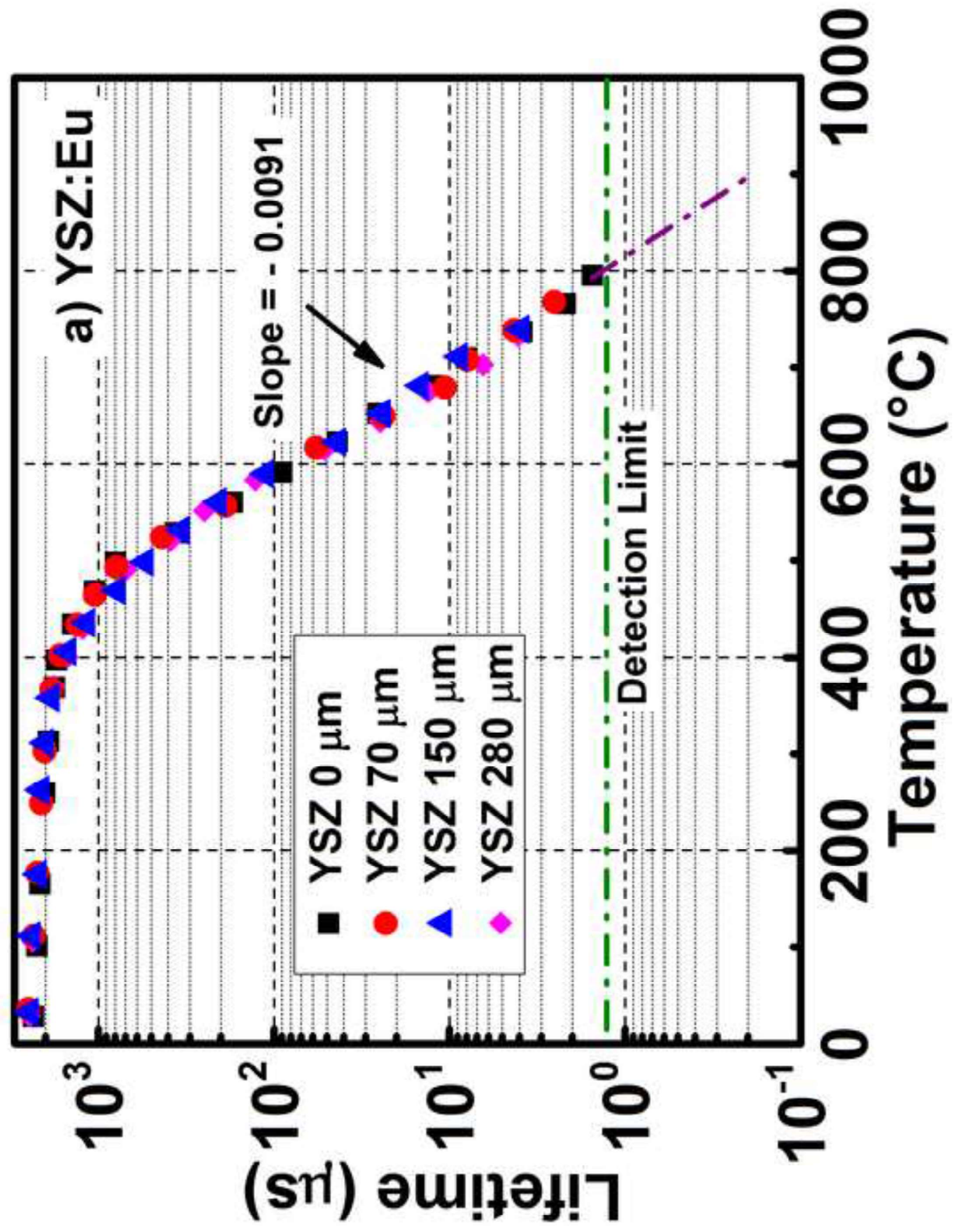




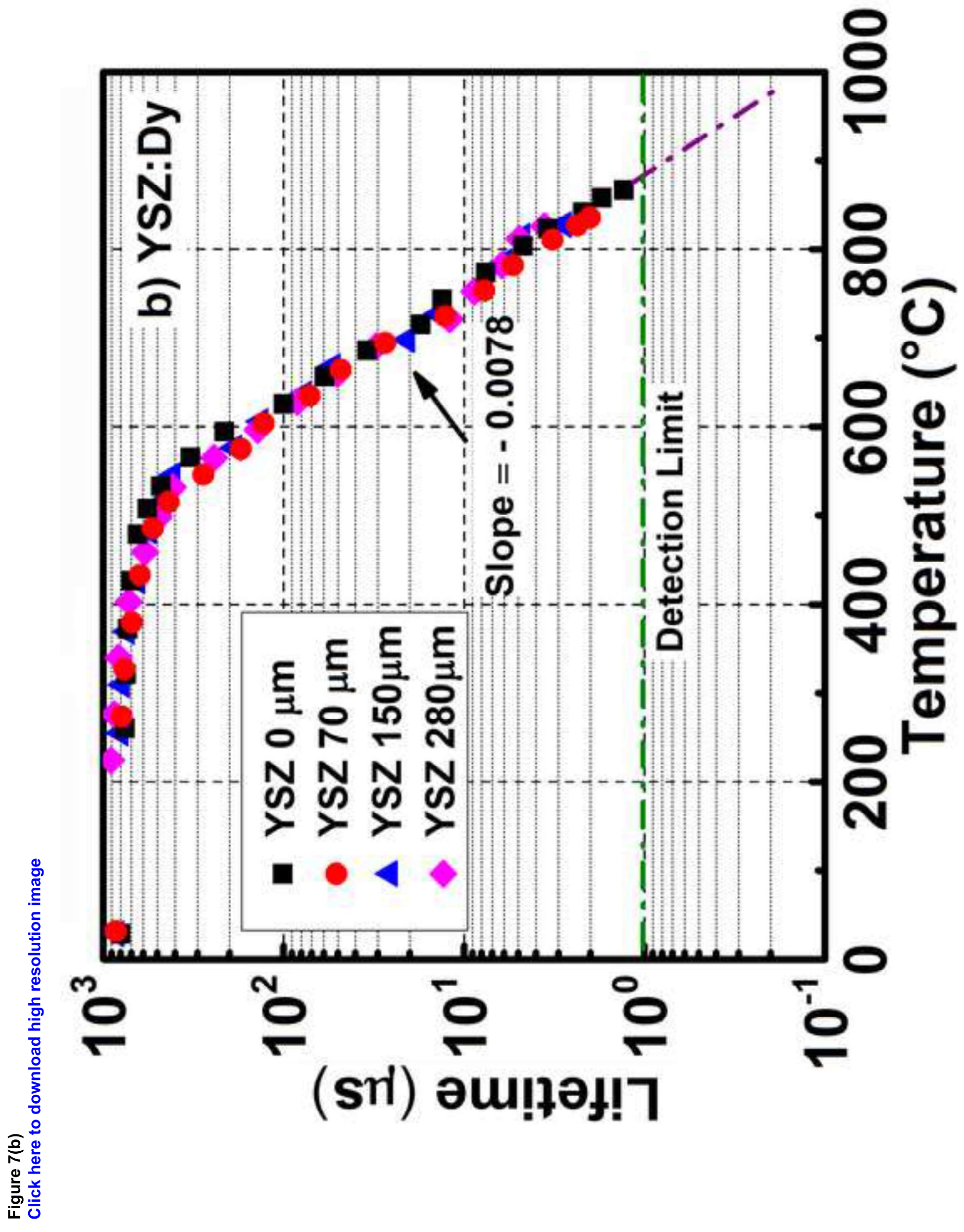




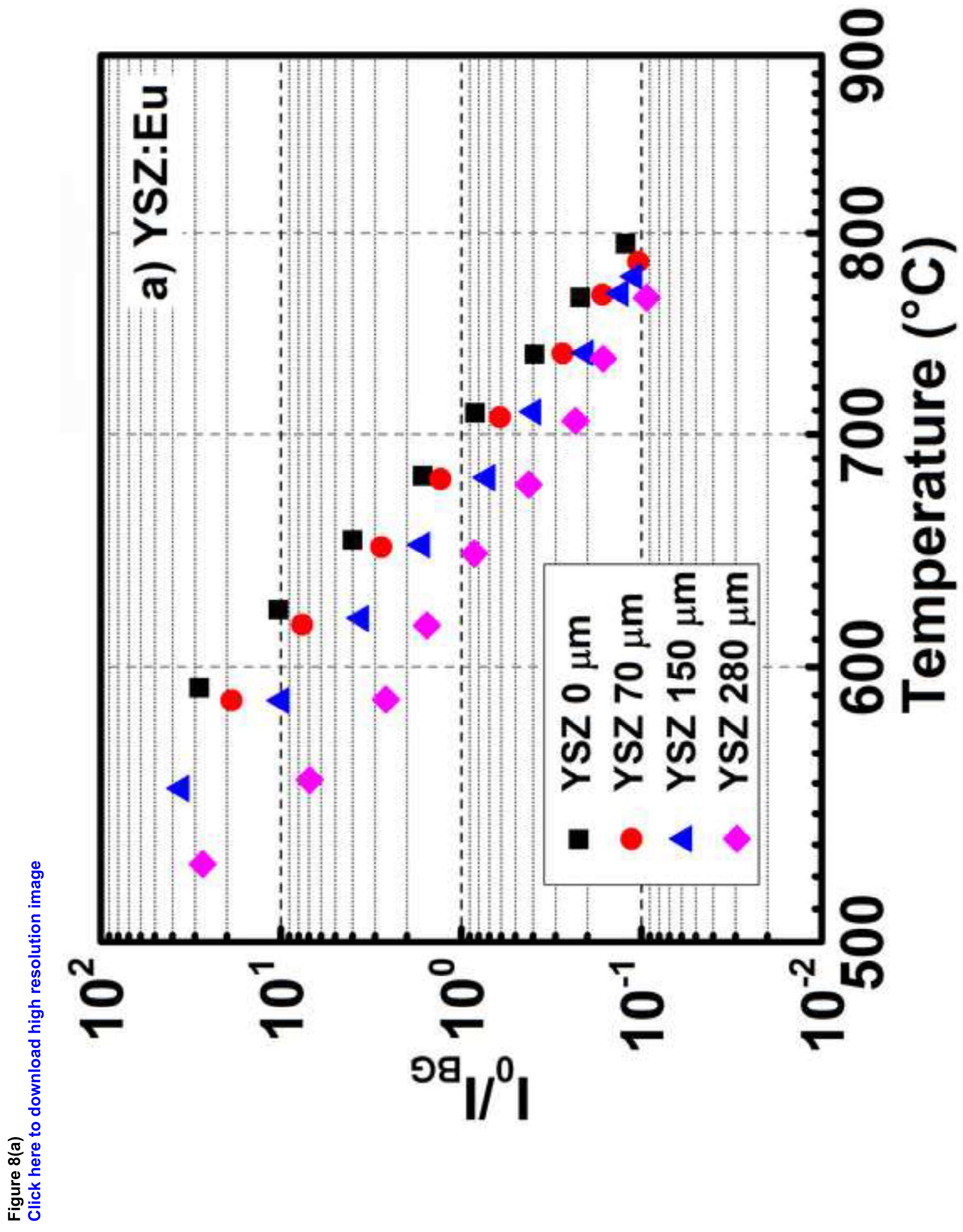




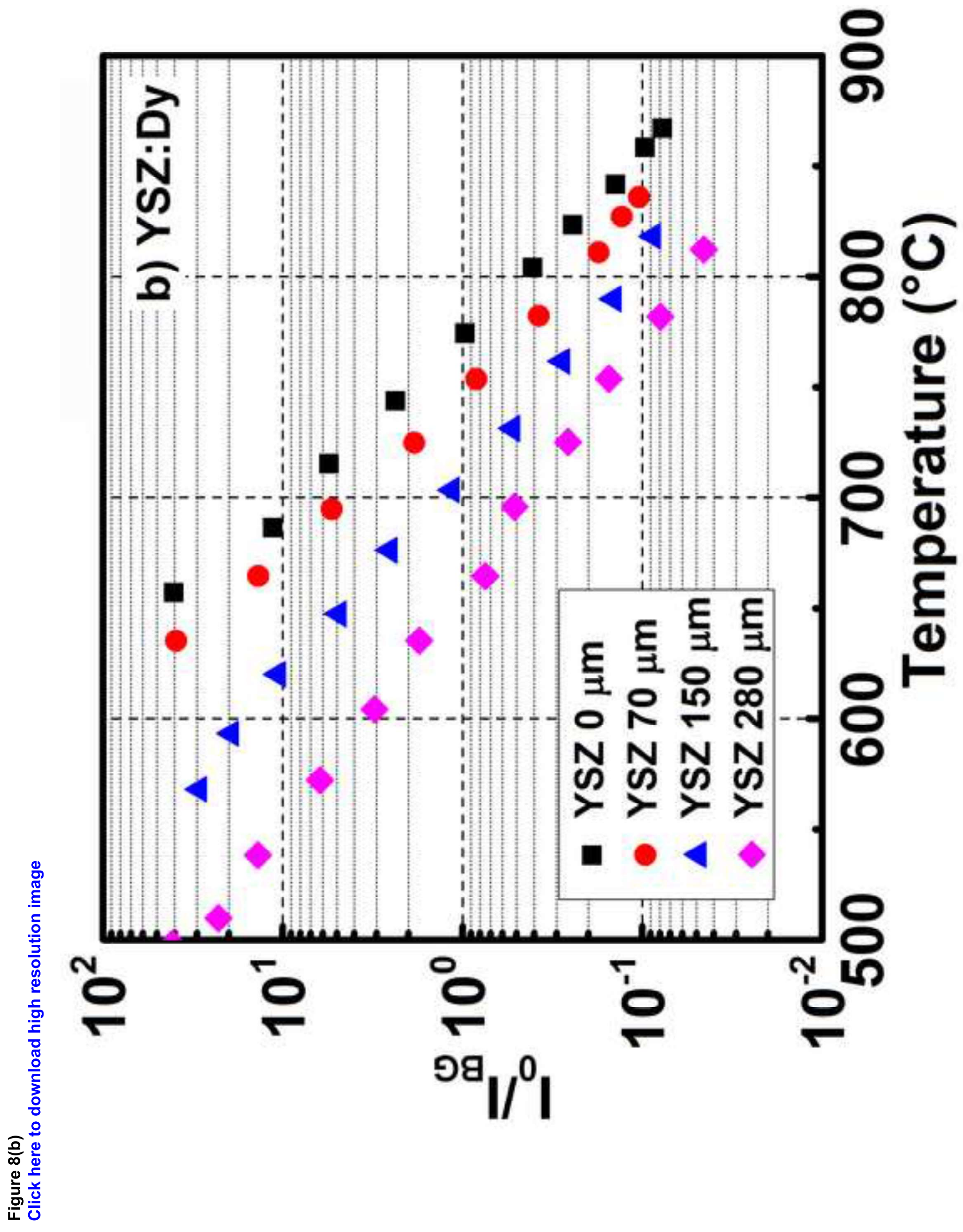




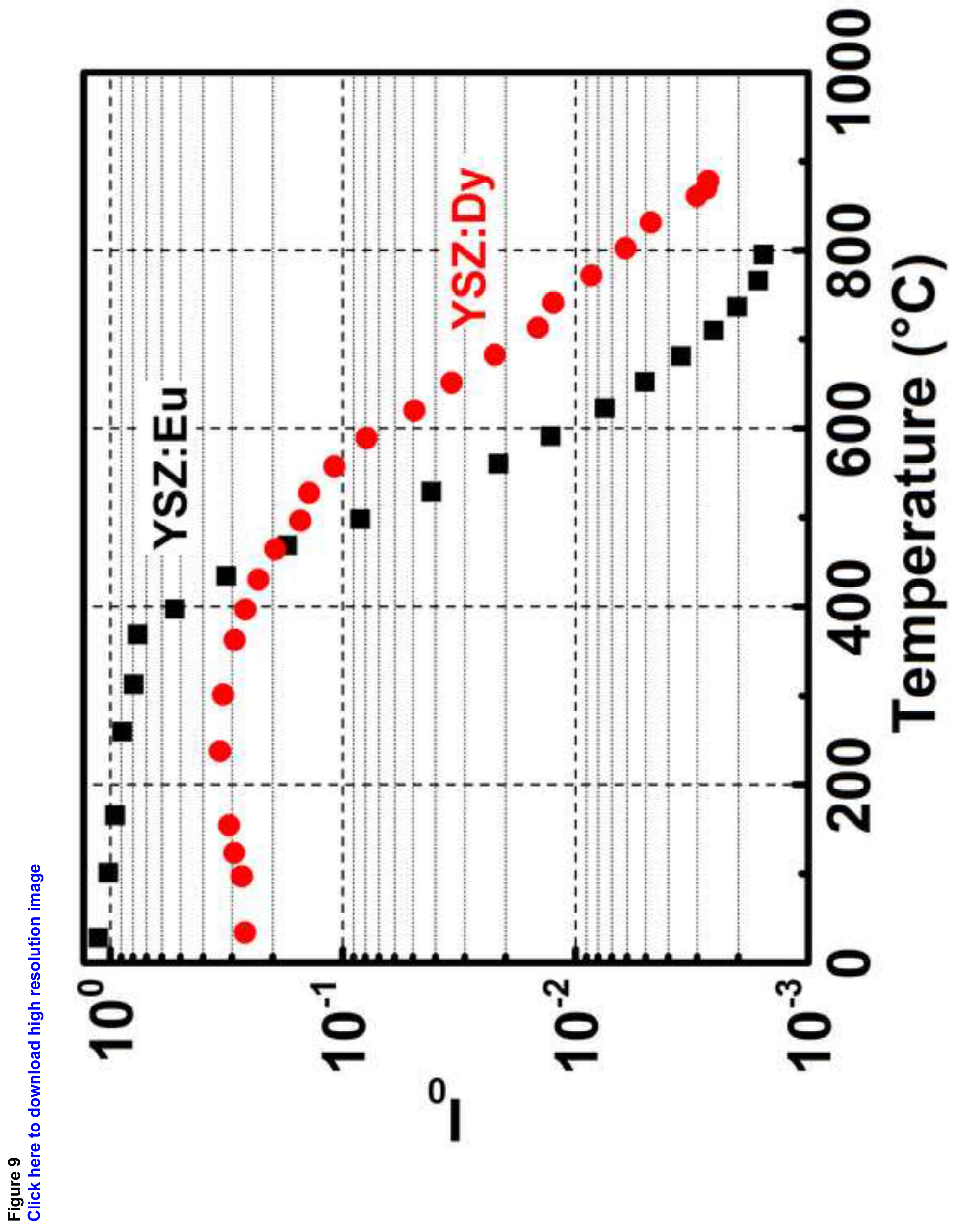




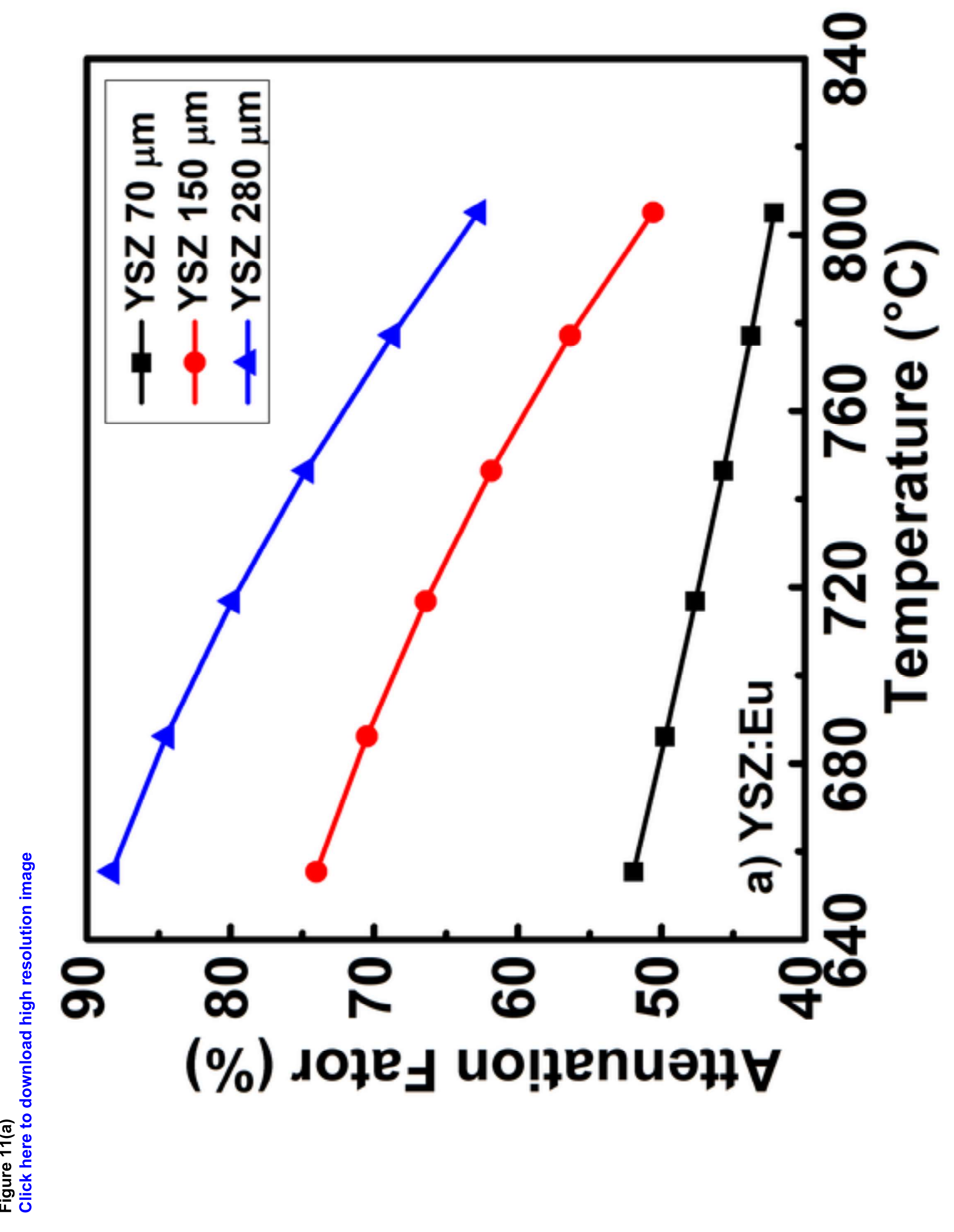




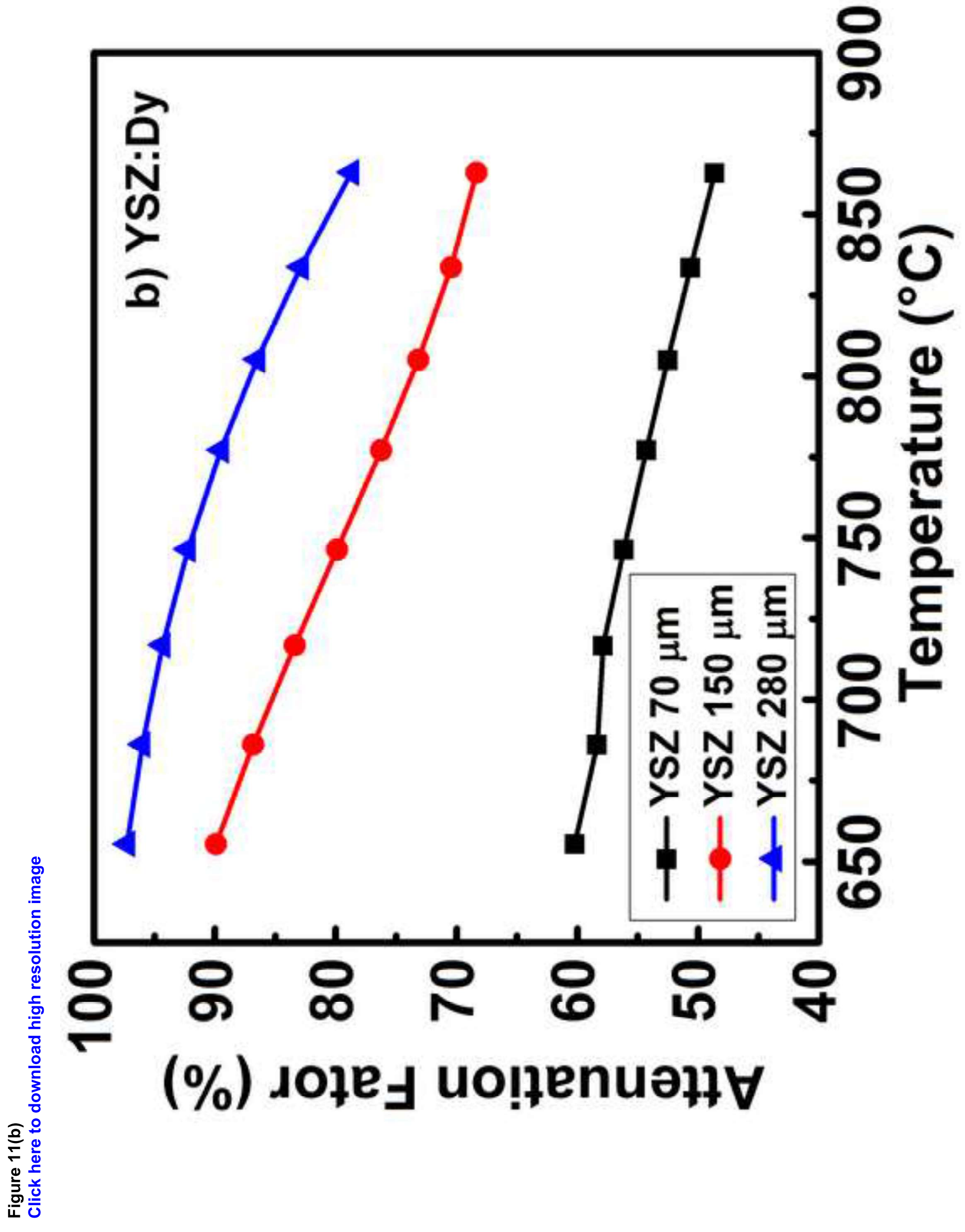




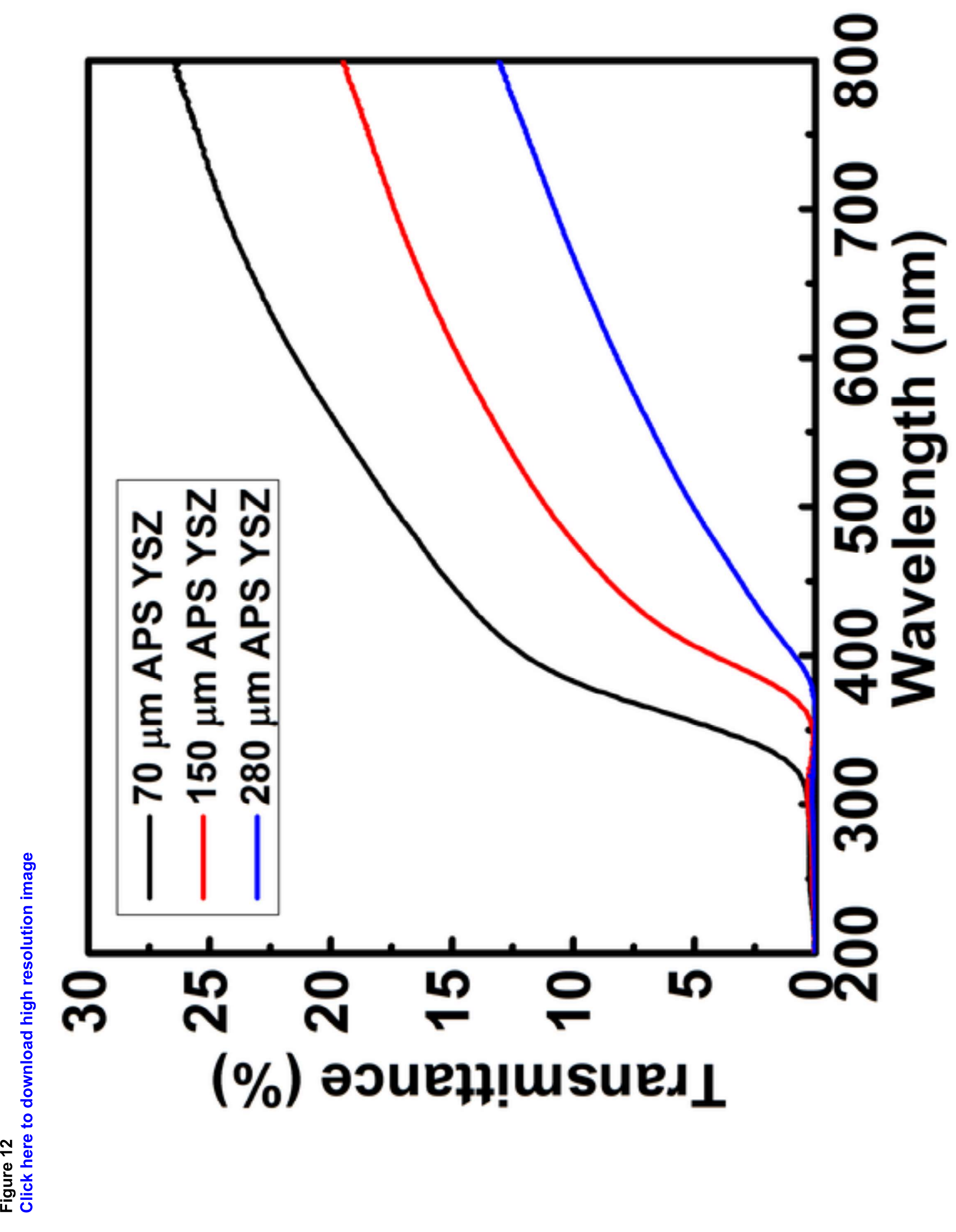




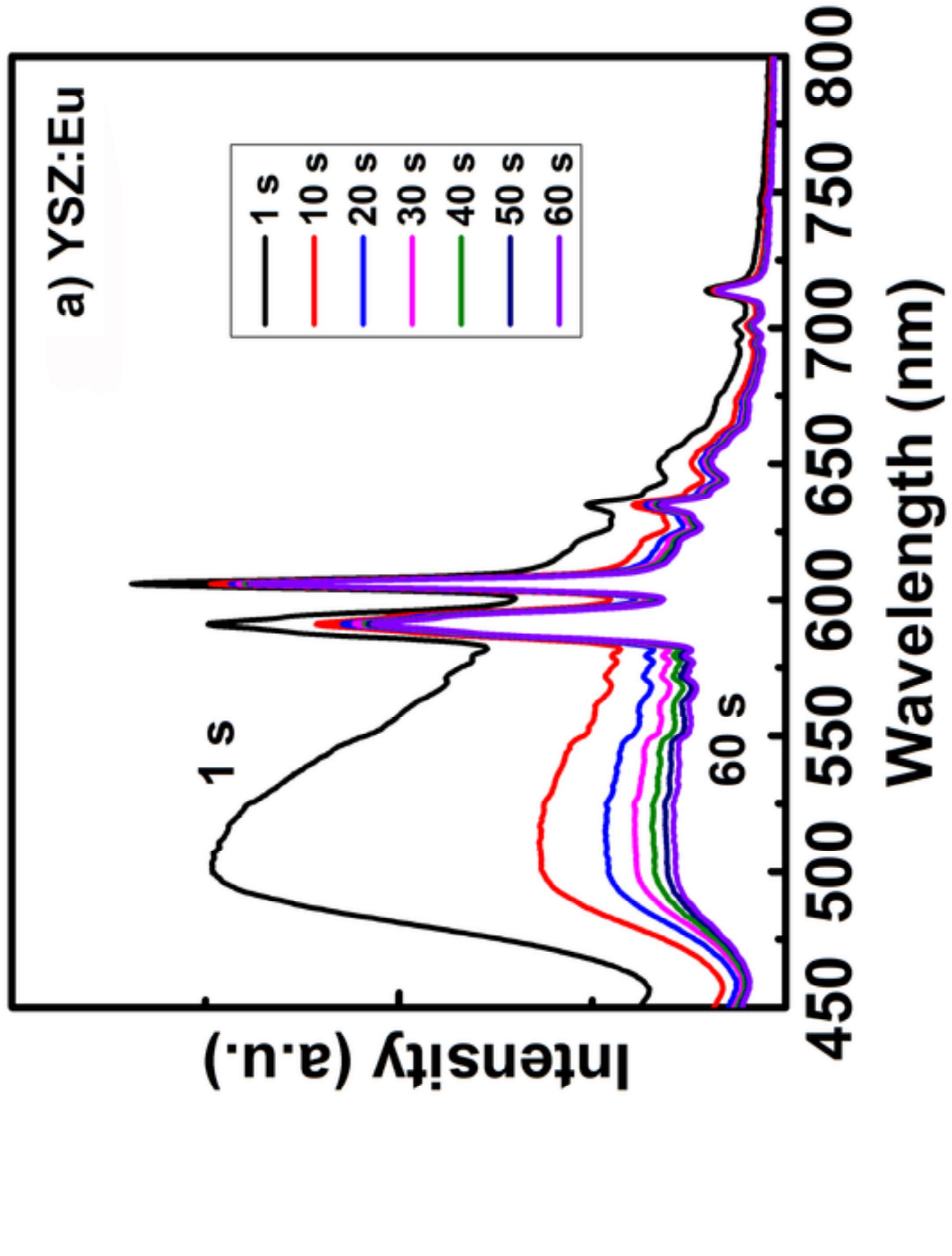




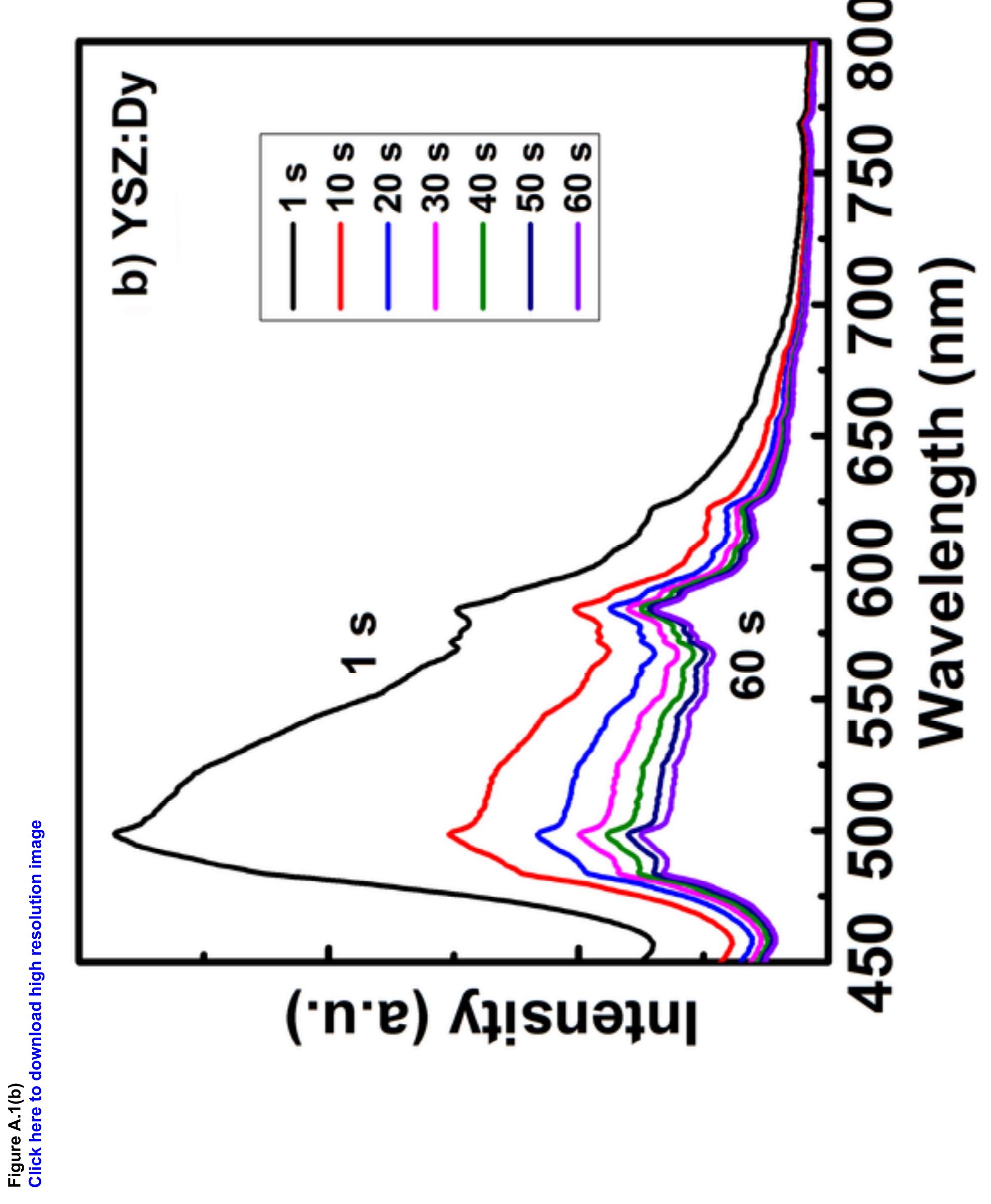




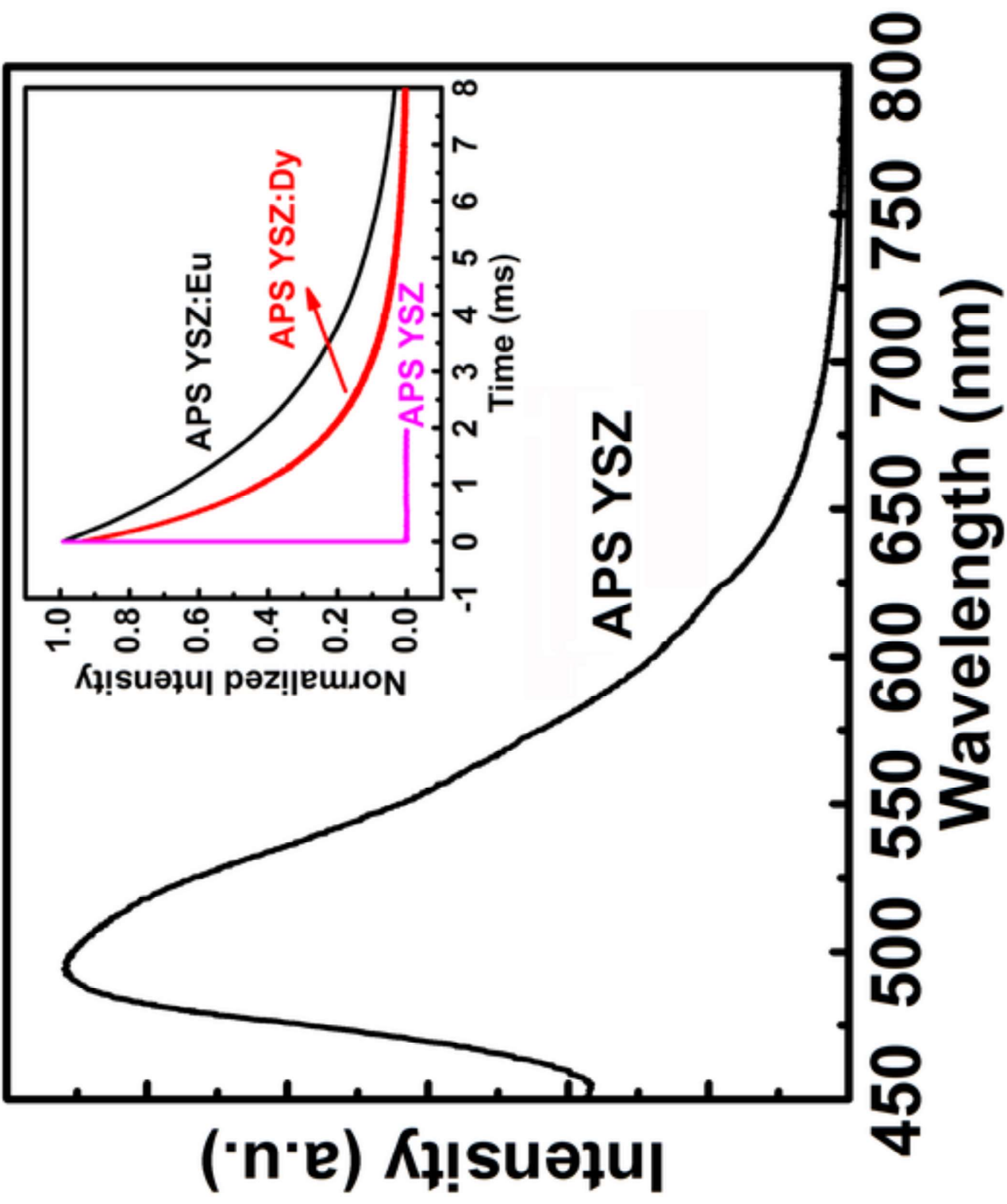




\section{Per Nylén}

Department of Engineering Science, University West, Sweden per.nylen@hv.se

Professor Per Nylén is one of world leading scientist in the processing of the thermal sprayed thermal barrier coatings.

\section{Xin Wang}

Department of Materials, Imperial College London SW7 2BP, UK xin.wang@imperial.ac.uk

Dr. Wang's research interests are in the broad areas of processing, characterization and performance of thermal barrier coatings.

Jörg P. Feist

Southside Thermal Sciences Ltd., Imperial College London, London, United Kingdom

j.feist@stscience.com

Professor Wu's work has included many studies involving sensor TBCs.

\section{Rudder $\mathrm{Wu}$}

Thermal Energy Materials Group, MANA, National Institute for Materials Science wu.rudder@nims.go.jp

Professor Wu's has long experience in thermal barrier coatings research. 

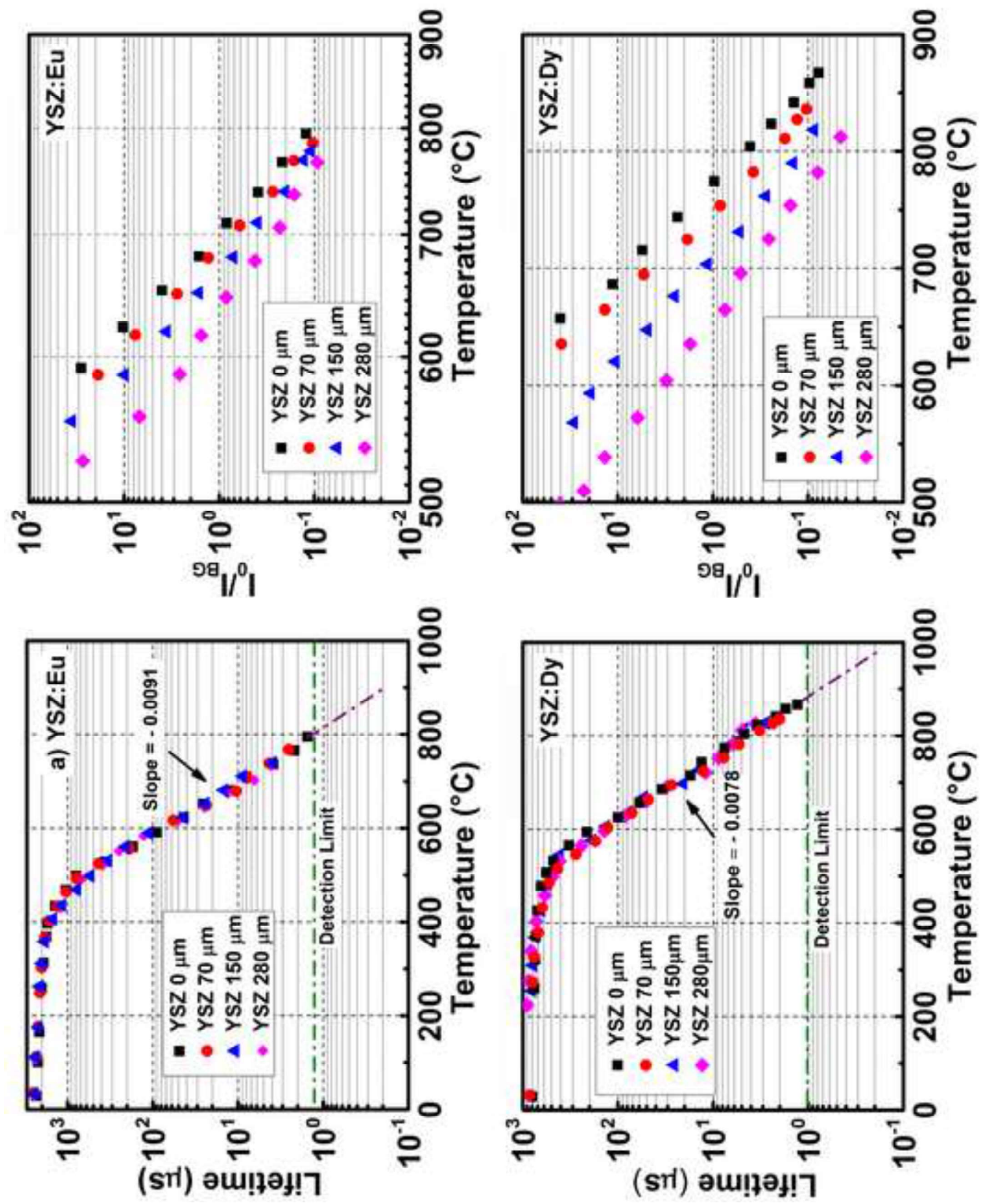